Marta Martins, Joana F. Guedes, Celeste Pereira, Stefan Forero, Volker Liedtke, Jiří Zelenka, Jan Václavík, Ernst Pfeiffer, Laurent Pambaguian, Advenit Makaya, Nuno Rocha

\title{
4 Carbon nanotube-based materials for space applications
}

\subsection{Introduction}

Carbon nanomaterials embedded in carbon fiber-reinforced composite materials can improve specific performance characteristics such as electrical conductivity, resistance to mechanical fatigue and crack propagation, structural damping, Passive Intermodulation (PIM) reduction, Electromagnetic compatibility (EMC) shielding, remachining and coating capabilities. Some of these improvements were investigated and demonstrated in the ESA projects "NACO-1" and "NACO-2" performed between 2007 and 2013. This chapter outlines the work performed during these activities for the development of carbon fiber-reinforced polymer (CFRP) composites integrating carbon nanotube (CNT) buckypapers (BP) to be used in space applications.

The ranking of space applications potentially benefitting CNT technology has been reviewed throughout these activities. The final activity is aimed at finally selecting an application with highest potential for performance improvements. For that, an optical CFRP mirror with comparable characteristics of conventional Zerodur-based mirrors featuring the inclusion of 3D nanotube structures was selected and manufactured.

Although CFRP composites are being used for reflectors in Space applications, due to its outstanding mechanical and thermal properties at low mass, optical mirroring properties are limited by the surface properties of the CFRP. One should note that each composite layer is composed of $1 \mathrm{D}$ and/or 2D patterns of continuous carbon fibers, each one of them having about $10 \mu \mathrm{m}$ of diameter, which are combined in tows of thousands of carbon fibers leading to a tow a few millimeters large. This configuration creates an undesired composite surface roughness, in a phenomenon usually known as print-through effect (Figure 4.1).

CFRP surface roughness limits its reflective properties. To afford further mirroring characteristics, polishing and metal coatings strategies can be followed. However, the

\footnotetext{
Marta Martins, Joana F. Guedes, Celeste Pereira, Nuno Rocha, INEGI - Institute of Science and Innovation in Mechanical and Industrial Engineering, Porto, Portugal

Stefan Forero, FutureCarbon, Bayreuth, Germany

Volker Liedtke, AAC - Aerospace \& Advanced Composites, Wiener Neustadt, Austria

Jiři Zelenka, TOSEDA s.r.o., Staré Čívice, Czech Republic

Jan Václavík, Institute of Plasma Physics of CAS, Prague, Czech Republic

Ernst Pfeiffer, HPS GmbH, München, Germany

Laurent Pambaguian, Advenit Makaya, ESA ESTEC, Noordwijk, Netherlands

Ә Open Access. (C) 2020 Marta Martins et al., published by De Gruyter. (c) BY-NC-ND This work is licensed under a Creative Commons Attribution-NonCommercial-NoDerivatives 4.0 International License.

https://doi.org/10.1515/9783110479133-004
} 


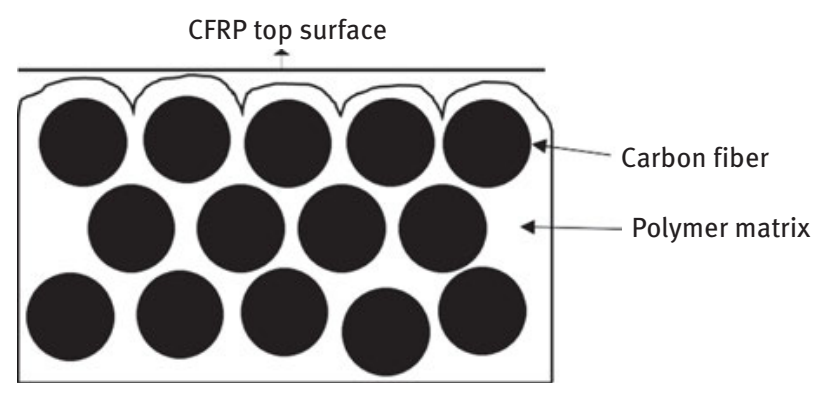

Figure 4.1: Representative image of print-through effect in a CFRP.

former is inherently limited by the continuous form of the carbon fibers, whereas the latter is also limited by the print-through characteristics of the CFRP. To overcome this limitation, inclusion of carbon nanotubes (CNT) at the top surface of the composites has been proposed as a solution to reduce its print-through behavior. In addition, the nearly isotropic nature of the CNT top layer is expected to ease polishing and metal coating processing. A material configuration in which a top layer of resin rich in CNT is added in the CFRP lay-up allows the reduction of the print-through effect on the manufactured CFRP and improves the reflective properties of the top surface.

The potential of CNTs is considered as tremendous; their intrinsic properties make them very attractive for Space applications where the characteristics of the materials often represent a limit to the development of technologies. Much of the development efforts have been focused on retaining CNTs large aspect ratio, achieving good interfacial stress transfer (surface modification), good dispersion and alignment in the polymer matrix during processing, all for maximizing the nanotubes effect. As a result, a growing number of companies already supply CNT-based masterbatches or compounds to be used in plastic/composite processing. Nevertheless, these materials are expensive, limited in the type of dispersing resin systems and on the CNT weight loading, and very difficult to incorporate in the conventional processes due to the very high viscosities.

In fact, one of the main difficulties that have been associated with the manufacturing of CFRP materials containing nanotubes is the poor processability of the resin systems modified with CNT, due to the extremely high viscosities. It is practically impossible to obtain a surface with quality when using high viscosity systems.

CNT BP consist of a 3D structure (skeleton) of CNTs either being single-walled (SWNT) or multiwalled or carbon nanofibers (CNF), which show a unique combination of inherent CNT/CNF properties while maintaining their lengths in a mat-like or 3D structure. These structures can be an alternative to overcome dispersion issues usually associated with the use of CNTs in resin masterbatches. In addition, higher CNT contents can also be attained by the use of three-dimensional CNT structures; therefore, CNT in the form of BP is a promising choice for boosting CFRP properties. 


\subsection{Preparation of epoxy nanocomposites based on high CNT content buckypapers}

The main objective of the first study was to develop and characterize highly loaded CNT-based nanocomposites, by infiltrating nanotube skeletons with either organic or inorganic matrix. We herein present the main results obtained with an organic thermoset (epoxy) resin.

A new approach was used to produce these CNT nanocomposites, where the CNT skeletons or papers were infiltrated with a low-viscosity epoxy resin in a closed mold. The CNT were first produced in thin papers called BP to form networks of elongated nanotubes. The impregnation was performed by infiltrating the resin along all the 3D CNT structure. The level of impregnation of the final structure was assessed by physical measurements and observations under scanning electron microscopy (SEM). The results showed that the proposed processing approach is capable of producing well-dispersed nanocomposites with high CNT loading (more than $12 \mathrm{wt} \%$ in resin weight), which are important for developing high-performance structures based on CNT with good thermal and electrical conductivity.

\subsubsection{Materials}

CNT thin papers, with $80 \mathrm{~mm}$ of diameter, functionalized (-COOH) and solvent (hexane or ethanol, EtOH) were produced by Future Carbon, $\mathrm{GmbH}$. The properties of the nanotubes used for the preparation of the skeletons are described in Table 4.1.

Table 4.1: Properties of the CNTs used for the development of buckypapers.

\begin{tabular}{lr}
\hline Property & \\
\hline Diameter $(\mathrm{nm})$ & $10-20$ \\
Length $(\mu \mathrm{m})$ & $20-40$ \\
Purity $(\mathrm{min}$ wt\% C) & $>98 \%$ \\
Number of walls & $5-15$ \\
\hline
\end{tabular}

The epoxy resin used to infiltrate the CNT skeleton was SR 8100 with SD 8824 hardener from SICOMIN. This system has low viscosity at room temperature (110 $\mathrm{mPa} \mathrm{s}$ ), facilitating the resin flow and impregnation of the skeletons. The gel time of about $1 \mathrm{~h}$ at $40{ }^{\circ} \mathrm{C}$ is suitable for a low-pressure infiltration. The recommended cure and postcure cycles for this system are $24 \mathrm{~h}$ at room temperature and $8 \mathrm{~h}$ at $60{ }^{\circ} \mathrm{C}$, respectively. 


\subsubsection{Sample manufacturing}

The impregnation of the CNT BP was performed at room temperature using a closed mold, as represented in Figure 4.2. For this mold, two spacers are available: one of $0.5 \mathrm{~mm}$ used for one layer composites and the other of $1 \mathrm{~mm}$ used for two layer composites. Three runs were performed using CNT papers with different chemical treatments, namely hexane or ethanol.

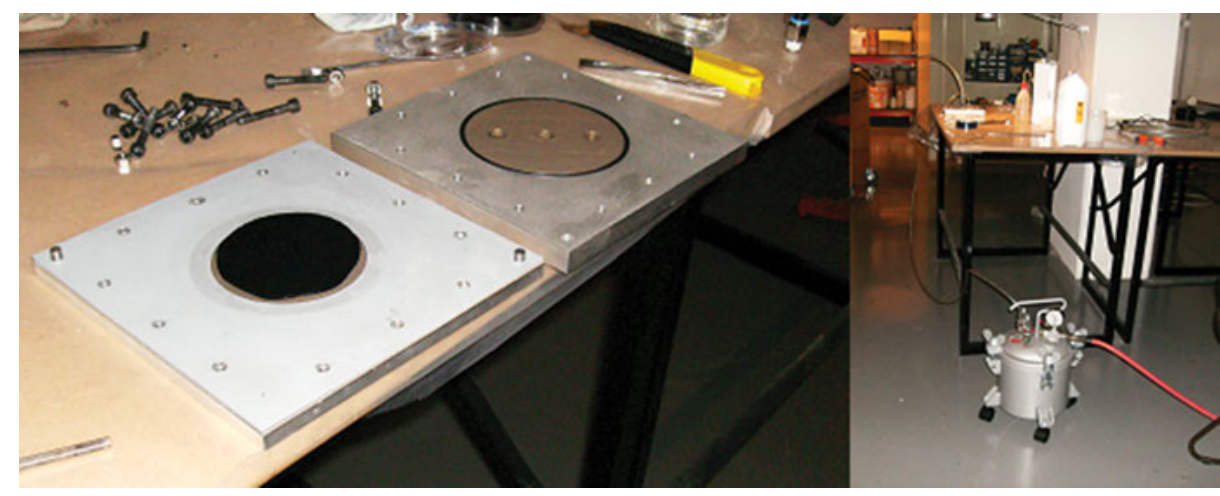

Figure 4.2: (Left) CNT skeleton positioned in the closed mold, before resin infiltration; (right) resin trap, placed before the vacuum pump, used to store eventual excess resin from the infiltration process.

The procedure used for the infiltration process can be roughly divided into the following steps:

1. Prepare the mold with the application of release agent

2. Put spacer in place

3. Place the CNT BP in the bottom mold

4. Close the mold

5. Connect the resin entry and the vacuum pump outlet

6. Turn on vacuum pump and verify if mold is completely sealed

7. Prepare the resin

8. Infiltrate the resin

The vacuum level used during the infiltration process was of 0.2 bar; the resin was injected in the mold at room temperature and the mold itself was kept at room temperature. The skeletons were allowed to cure $24 \mathrm{~h}$ at room temperature inside the mold, followed by demolding and postcure cycle in an electrical oven. 


\subsubsection{Characterization}

CNT papers and composite samples were visual inspected, measured and weighted before and after infiltration. Fractured surfaces of samples were observed under a high-resolution SEM for the level of impregnation and surface quality assessment, as well as for measurements of the nanotube and resin layer thicknesses.

\subsubsection{Results and discussion}

\subsubsection{Physical characterization}

Figure 4.3 shows an SEM image of the BP surface (a), appearance of a CNT paper before (b) and after (c) infiltration. CNT papers have good strength and flexibility to allow handling like carbon fiber mat. The SEM image (a) shows that CNT possess diameters in the range of $10-20 \mathrm{~nm}$ and lengths in the range of $20-40 \mu \mathrm{m}$. CNT are produced solely by catalytic chemical vapor deposition as described elsewhere [1]. The number of walls is between 5 and 15 .

Table 4.2 summarizes the main physical characteristics of the CNT papers used and of the nanocomposites obtained, namely the thickness and mass values. The CNT BP papers used in the manufacturing of samples 1 and 2 are hexane treated and the one used for sample 3 is ethanol treated. The thickness of the CNT papers is uniform, ranging from 350 to $375 \mu \mathrm{m}$.

After resin infiltration, the CNT BP thicknesses increase more than doubling its value. This increase is, however, very close to all samples, in the range of 405-430 $\mu \mathrm{m}$. The mass of the obtained nanocomposites ranges between 3.11 and $3.98 \mathrm{~g}$ and the CNT weight content calculated directly (from the variation of mass before and after infiltration) is between $11.6 \%$ and $15.4 \%$ [2]. The higher CNT content was obtained for sample 1, with hexane-treated nanotubes. From these results we cannot conclude about a relation between solvent treatment and CNT content in the composite. Sample 2 is the one that has higher mass and consequently lower CNT content. This is due to the higher amount of resin that infiltrated the paper. The infiltration process shall be controlled in order to achieve highly loaded CNT composites, the reproducibility of the process and thus be able to conclude on the effect of the paper solvent treatment on composite properties. 


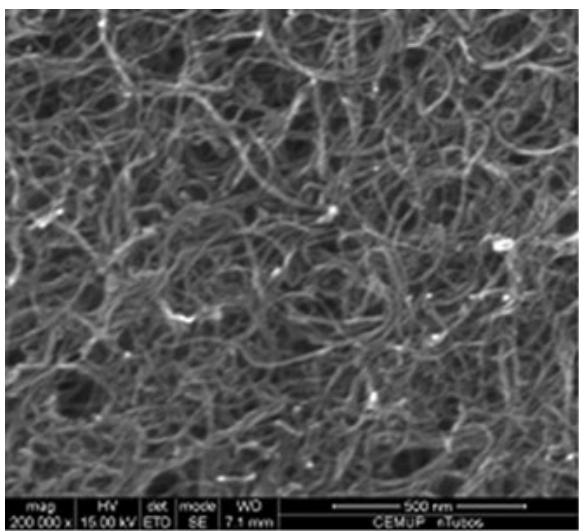

(a)

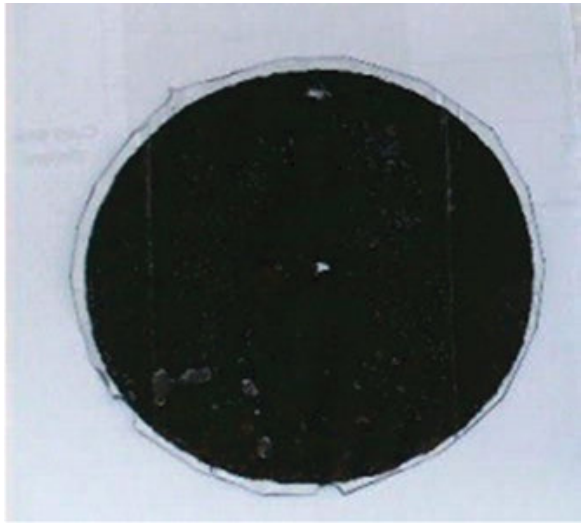

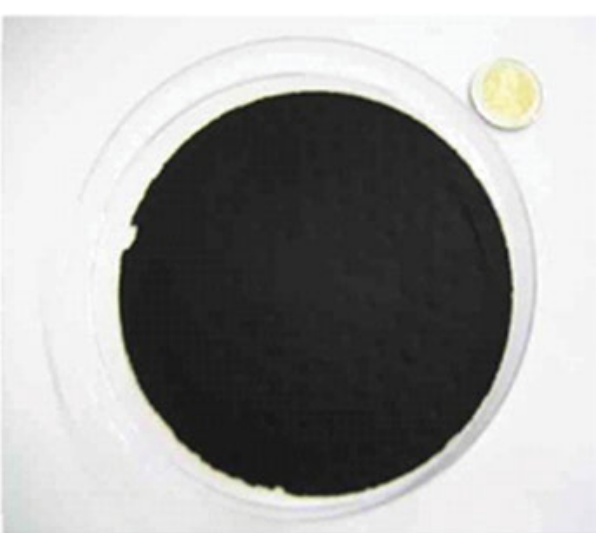

(b)

(c)

Figure 4.3: SEM image of the buckypaper surface (a) and the aspect of the buckypaper before (b) and after infiltration (c).

Table 4.2: Summary of the CNT papers and nanocomposite characteristics.

\begin{tabular}{lrrrrrrr}
\hline Sample & \multicolumn{3}{c}{ CNT paper } & & \multicolumn{3}{c}{ Nanocomposite } \\
\cline { 2 - 3 } & Solvent & Thickness $(\mathrm{mm})$ & Mass $(\mathbf{g})$ & & Thickness $(\mathrm{mm})$ & Mass (g) & CNT wt\% \\
\hline 1 & Hexane & 0.350 & 0.4798 & & 0.760 & 3.11 & 15.4 \\
2 & Hexane & 0.370 & 0.4616 & & 0.803 & 3.98 & 11.6 \\
3 & Ethanol & 0.375 & 0.4576 & & 0.780 & 3.27 & 14.0 \\
\hline
\end{tabular}

\subsubsection{Structure observations}

In Figure 4.4, two microscopic pictures are presented, which are obtained under two magnifications and from different locations along the thickness of the sample 1 . It is 


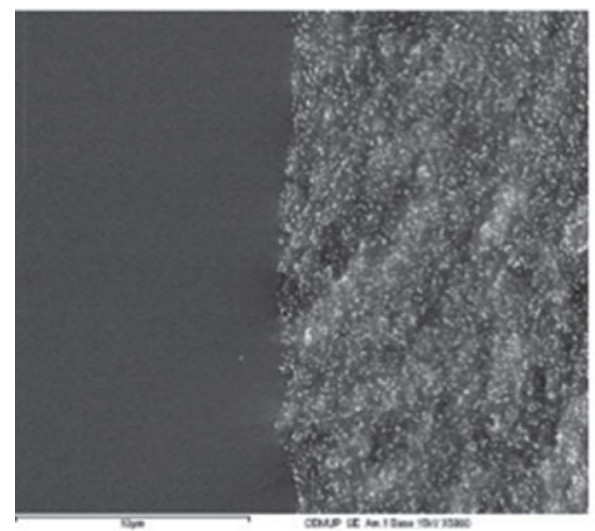

(a)

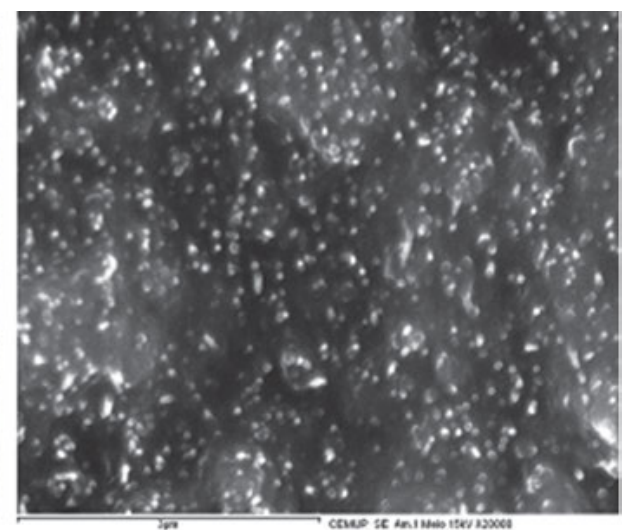

(b)

Figure 4.4: SEM pictures of sample 1 (a) in the bottom side of the composite and (b) in the middle of the composite.

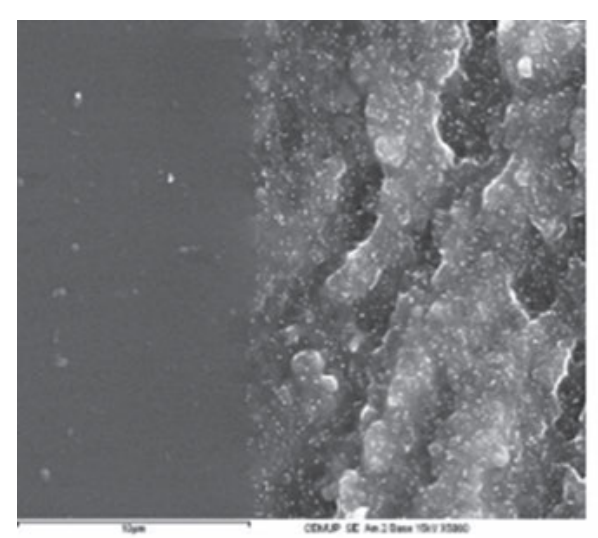

(a)

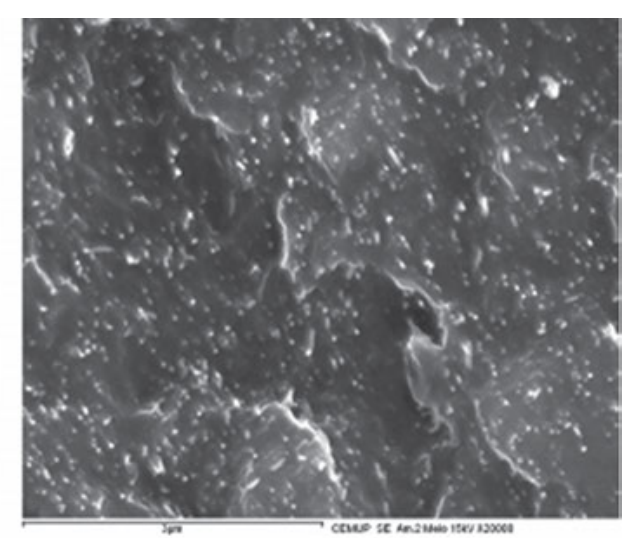

(b)

Figure 4.5: SEM pictures of sample 2 (a) in the bottom side of the composite and (b) in the middle of the composite.

possible to observe a thick layer of resin (more than $0.2 \mathrm{~mm}$ ) located in the bottom side of the sample and nanotubes well impregnated by resin in the middle of the sample.

Figure 4.5 presents two microscopic pictures for sample 2. As for sample 1, a rich resin layer is observed in the bottom side (lower than $0.2 \mathrm{~mm}$ ) and upper side (lower than $0.100 \mathrm{~mm}$ ) of the sample, and a good matrix infiltration in the middle is witnessed.

Figure 4.6 shows the pictures obtained for the third run sample. It is observed that the BP does not maintain the initial form (appearing slightly curved in the images) and their thickness is variable along the diameter. Once again, a thick layer of 


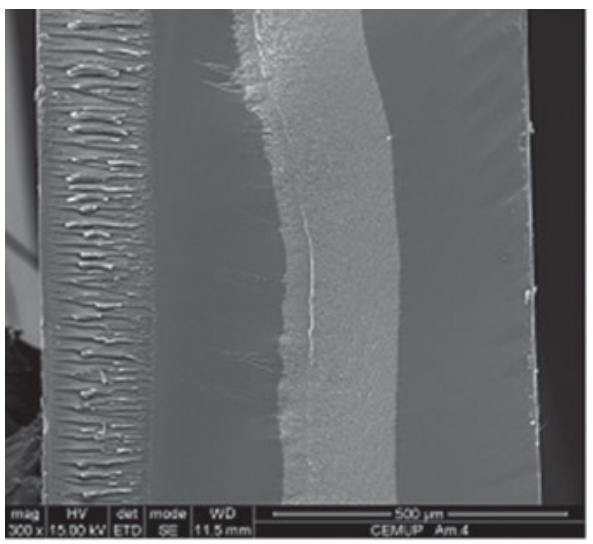

(a)

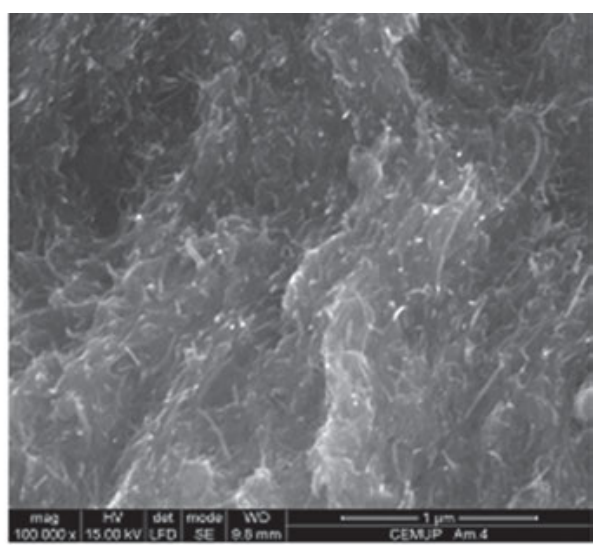

(b)

Figure 4.6: Composite SEM pictures of the third run sample: (a) along the thickness of the composite and (b) in the middle of the composite.

resin is covering the paper. In fact, it is possible to see that the thickness of the resin layer is much higher then the CNT BP one. Once more, a good matrix infiltration in the middle is observed.

Table 4.3 summarizes the measurements of the top and bottom resin-rich layers and CNT paper thicknesses, after the infiltration process, measured from the SEM observations. It is observed that the thickness of the paper does not remain unchangeable, since it swells for samples 1 and 2 and shrinks considerably for sample 3.

Table 4.3: Resume of the characteristics of CNT papers and CNT nanocomposites.

\begin{tabular}{lrrrr}
\hline Sample & \multicolumn{4}{c}{ Nanocomposite } \\
\cline { 2 - 5 } & $\begin{array}{r}\text { CNT thickness before } \\
\text { resin infiltration } \\
(\mathrm{mm})\end{array}$ & $\begin{array}{r}\text { CNT thickness after } \\
\text { resin infiltration }(\mathrm{mm})\end{array}$ & $\begin{array}{r}\text { Thickness of } \\
\text { resin layers } \\
\text { (top + bottom) }\end{array}$ & $\begin{array}{r}\text { CNT wt\% } \\
\text { (eliminating } \\
\text { resin-rich layers) }\end{array}$ \\
\hline 1 & 0.350 & 0.428 & 0.366 & 34.8 \\
\hline 2 & 0.370 & 0.462 & 0.282 & 17.4 \\
\hline 3 & 0.375 & 0.220 & 0.624 & 47.4 \\
\hline
\end{tabular}

Two possible explanations for this can be prompted: the first one is that the solvent treatment has an effect on the resin behavior - contraction or expansion - during the cure [3]; the second is that the solvent treatment increases or decreases the infiltration of the resin into the paper, either by changing the wettability or the permeability of the CNT papers [4]. P.E. Lopes and coauthors [5] studied the wettability (by contact 
angle measurements) of CNT BP with different treatments. However, the CNT treatments studied were heat, carboxyl or nonfunctionalized, which are different than the ones reported here.

A rough estimation of the possible CNT content that could be achieved, if the resin-rich layers were eliminated, calculated and presented in Table 4.3. The most surprising results are the differences between samples 1 and 2, which have the same CNT treatment. The second sample has the lower CNT content and confirms the high portion of resin in the composite. Once more, we conclude that the infiltration process should be well controlled, and a release film must be used in the surfaces of the CNT papers intended for reducing the thickness of top and bottom layers of resin and the permeability of the CNT papers accessed. The resin content is a critical aspect of this CNT composites, since the excess of resin can affect negatively some properties, namely the thermal and electrical conductivity as well the mechanical properties [6-8].

These extrapolated results of CNT content (presented in Table 4.3) are more in agreement with those reported in literature [9]. Wang and coworkers have prepared SWNT BP/epoxy resin nanocomposites by using very thin papers $(0.1-0.5 \mathrm{~mm})$ stacked together in a hot press machine. The resin was infiltrated in papers after being diluted with acetone due to its high viscosity (2,700 $\mathrm{mPa} . \mathrm{s})$. They produced nanocomposites with SWNT loadings as high as 39\% with nanopore sizes in the BP in the range of 100-200 $\mathrm{nm}$.

\subsubsection{Conclusions}

It was the purpose of this experimental work to produce CNT/epoxy resin composites by infiltrating a low-viscosity epoxy resin in membranes of nanotube networks called BP, supplied by Future Carbon. The CNT content achieved in the composites is between $11.6 \%$ and $15.4 \%$ in weight. In all the SEM observations of the composites produced, there is evidence that there is a good level of impregnation, yet the resin layer around the CNT BP is very thick. The process must be optimized in order to obtain composites without excess of resin in the surfaces, since the resin affects negatively some properties of the composites, namely the thermal and electrical conductivity as well the mechanical properties.

\subsection{Manufacturing process scale-up and integration into CFRP composite structures}

The main purpose of project NACO2 was the scale-up processing of CNT BP and their integration on CFRP composites. In order to find the most suitable manufacturing method, a number of tests were planned taking into account critical aspects of the 
manufacturing parameters (such as mold materials, vacuum and pressure levels during curing and resin impregnation temperature) [9]. Based on this, several manufacturing runs were experimentally performed, aiming to obtain high-quality CNT-CFRP composites. From these runs, it was concluded that the use of a steel mold coated with Teflon release films, combined with manual resin impregnation at room temperature and cure in the autoclave under vacuum and pressure lead to improved materials. At the end of the project, a CNT-skeleton composite demonstrator was obtained; herein we present the manufacturing details of that demonstrator.

\subsubsection{Materials}

Oxidized CNT skeletons in paper containing binder were used. The epoxy resin system used was: Araldite LY556, Aradur HY906 and Accelerator DY070, manufactured by HUNTSMAN, Switzerland. A Style 450/T300 Plain Weave $140 \mathrm{~g} / \mathrm{m}^{2}$ carbon fiber fabric of Cramer Fabrics, Germany, was used for the manufacturing of the demonstrator. Table 4.4 presents the characteristics and suppliers of the raw materials used for manufacturing the polymer demonstrator.

Table 4.4: Resume of the materials used in CNT-polymer demonstrator.

\begin{tabular}{lll}
\hline Materials & Main characteristics & Supplier \\
\hline CNT skeleton & Oxidized CNTs, paper form, with binder & Future Carbon \\
Resin & Epoxy system (LY556 + HY906 + DY070); pot-life: & Huntsman \\
& $50-55 \mathrm{~h}$ at $25^{\circ} \mathrm{C} ;$ viscosity: $1,900-2,100 \mathrm{mPa} \mathrm{S}$ & \\
Carbon fiber & CF Style $450 / \mathrm{T} 300$ Plain Weave $140 \mathrm{~g} / \mathrm{m}^{2}$ & CC Fabrics \\
\hline
\end{tabular}

The CNT skeleton was produced by tape casting and has a binder amount of $29 \%$ in weight. The thickness is about $70 \mu \mathrm{m}$, as measured by optical microscopy and the size was $107 \times 11 \mathrm{~cm}^{2}$.

\subsubsection{Sample manufacturing}

The demonstrator was produced by hand lay-up followed by vacuum bagging in the autoclave and using Teflon as release film. The resin was applied at room temperature between all the reinforcement layers, and the CNT BP was applied as the top layer. The "striped" surface of the CNT skeleton (BP side that was cast in the release film) was faced toward the CFRP material during the impregnation. No resin in the top layer (on the BP) was applied. The pressure used in the autoclave was of $3 \mathrm{bar}$, the vacuum level was of 150-250 mbar and the temperature program was $2 \mathrm{~h}$ at $120{ }^{\circ} \mathrm{C}+2 \mathrm{~h}$ at $180^{\circ} \mathrm{C}$. Figure 4.7 shows the different stages of the demonstrator manufacturing. 


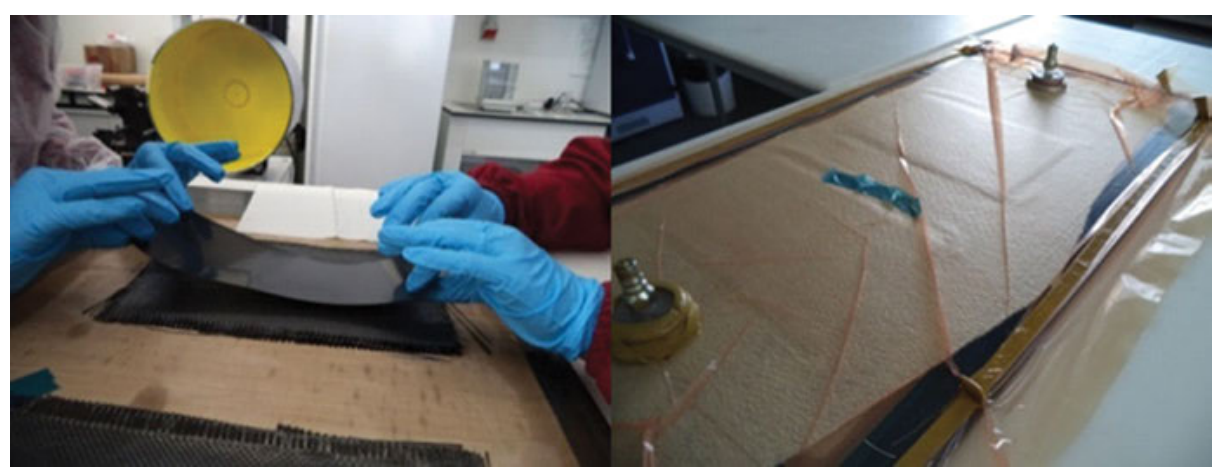

Figure 4.7: Different stages of the manufacturing process of the demonstrator.

\subsubsection{Results and discussion}

\subsubsection{CNT skeleton handling}

Since the CNT skeleton used had a very low thickness $(70 \mu \mathrm{m})$, it was important that the material is very well conditioned. Also, due to its large size, it is crucial to be easy to manipulate so the composite manufacturing process is feasible. The CNT skeleton used in the demonstrator was packaged between two polymer substrate foils. The upper substrate foil was very easy to remove; however, the lower foil was completely "glued" to the BP. The cutting of the structure was easily performed with the use of supporting plates to maintain the CNT BP immobile and fully supported. Figure 4.8 shows two pictures of the conditioning and handling of the skeleton.

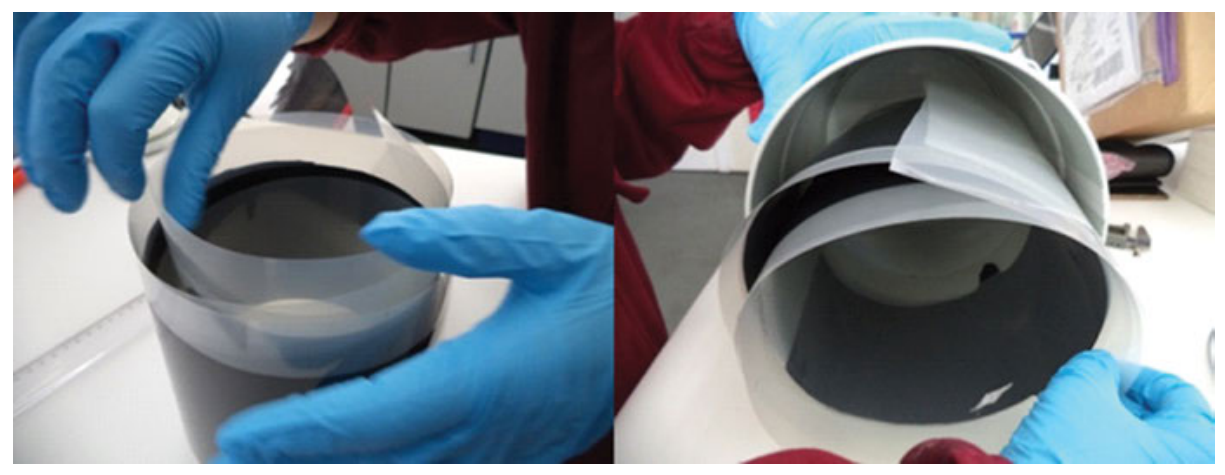

Figure 4.8: Conditioning, handling and aspect of BP used for manufacturing the demonstrator. 


\subsubsection{CNT skeleton preparation}

As mentioned earlier, the BP was "glued" to the supporting foil. The procedure for removing the CNT paper, used in the demonstrator, from the casting substrate is given as follows:

1. cutting of the edges with the aid of supporting plates;

2. face the supporting film upward;

3. release a film tip with the aid of a tweezer;

4. separate the film from the BP using a metallic roller, while pulling the film upward and

5. continue until both materials are completely separated.

Figure 4.9 shows the sequence of procedures performed to separate the CNT skeleton from the supporting foil. It can be seen that the face of the BP that was "glued" to the polymer foil showed a different aspect, where a "striped" pattern is clearly visible. This stripped surface was faced toward the CFRP material during the impregnation run.

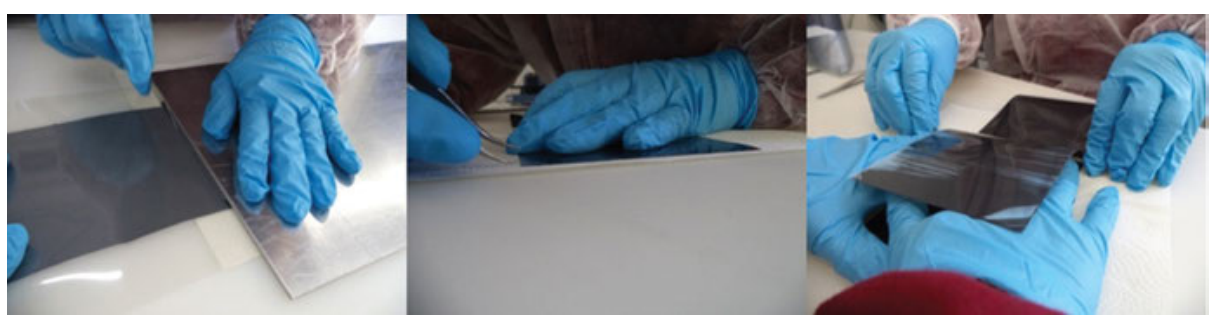

Figure 4.9: Procedure used for cutting and removing the supporting film from the buckypaper.

\subsubsection{Visual inspections}

Figure 4.10 shows the aspect of the whole sample after curing cycle and demolding, as well as samples already cut and ready for characterization tests. Some cracks in the BP were visible in the corners of the samples, after the cutting procedure. This can be due to either (i) lack of adhesion of the BP to the CFRP and/or (ii) the poor impregnation of the BP.

\subsubsection{Structure observations}

Figure 4.11 shows the resulting SEM pictures of the demonstrator. The SEM images show that, in some extent, the BP is separated from the CFRP laminate. The level of impregnation of the fibers seems good, and only a small resin layer (50-90 $\mu \mathrm{m})$ is 


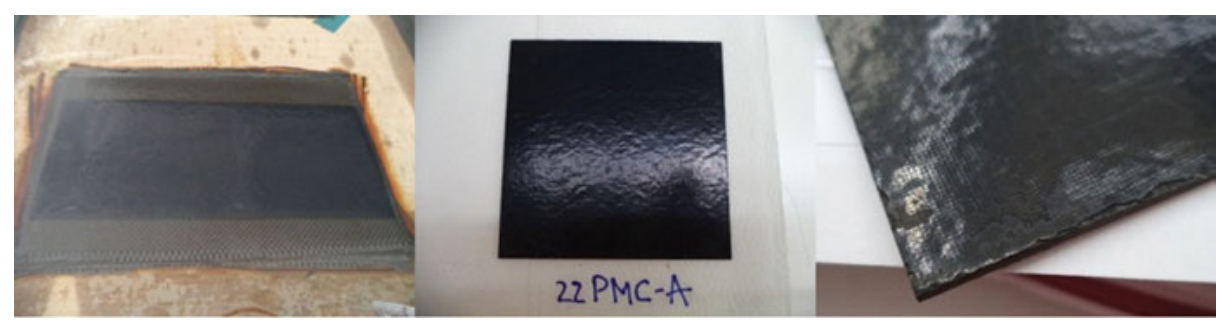

Figure 4.10: Polymer demonstrator photographs.

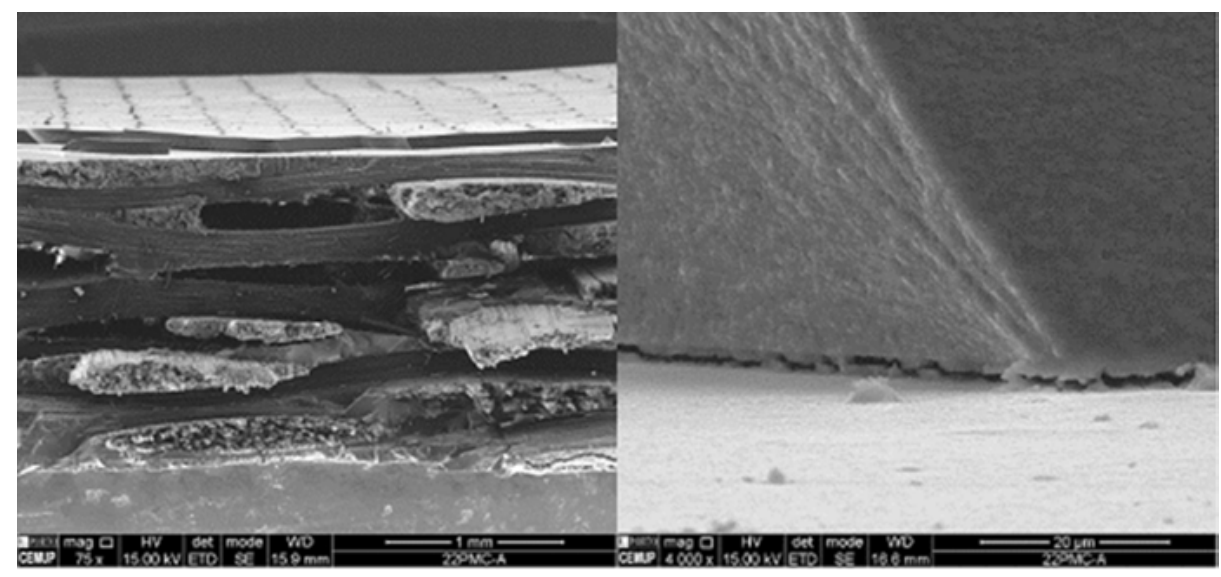

Figure 4.11: Polymer demonstrator photographs.

visible on the bottom surface. As previously mentioned, it is visible that the BP is not bonded to the laminate.

\subsubsection{Conclusions}

A small demonstrator was manufactured with the main following objectives:

1. to evaluate the quality of packaging;

2. to assess the hand ability of large and thin BP;

3. to determine the effect of the autoclave cycle on the BP's binder;

4. to verify the level of wettability and quality of impregnation of the BP of drop of resin and

5. to demonstrate that the manufacturing of large composites with large and very thin CNT layers is feasible. 
The main conclusions from this activity can be summarized as follows [10, 11]:

- The CNT paper packaged between two polymer substrate foils and rolled inside a metallic container is effectively protected.

- BP can be easily manipulated when confined between the substrate foils. However, the removal of the lower substrate requires additional caution.

- The most significant change on the BP after autoclave cycle is the appearance of a layer of polymer (binder) in the surfaces of the skeleton.

- The resin spreads quite easily in the surface (nonstriped) and is able to enter into the material.

- The manufacturing of large composites with large and very thin CNT layers is feasible. However, some improvements or additional studies must be done, since the BP and the laminate were poorly bonded.

\subsection{Technology demonstration in CFRP mirrors for space applications}

The aim of NATAP activity was to identify, develop and test two selected demonstrators with functional CNT layers. Due to the high variety of options for adapting material properties, an initial trade-off was conducted to identify various space products, where the effect and the possibility of implementation would be maximized. Based on previous development activities, a large number of applications have been investigated in detail with respect to the likelihood to be used in the near future and with potential for improvement of weight, cost, performance and resistance to environmental impacts. From these, an optical mirror with comparable characteristics of conventional Zerodurbased mirrors was selected [12]. The realized demonstrator (28 cm diameter) consists of a sandwich structure, composed of CFRP honeycomb. CFRP face sheet and an infiltrated CNT BP, which serves as a "grindable surface" for highest accuracy. This surface was finally coated with a metal layer (by vapor deposition of aluminum coating and top protective $\mathrm{SiO} / \mathrm{SiO}_{2}$ coating layer) for optical reflectivity in the appropriate wavelength.

\subsubsection{Materials}

FutureCarbon was in charge of providing a dense CNT-based paper or nonwoven structure to be used as top carbon layer on the concave (optical) side of the mirror surface. From the manufacturing point of view, the CNT paper was the first layer on the mold surface. The CNT papers were manufactured using a filtration process, which resulted in $4-5 \mathrm{wt} \%$ of $-\mathrm{COOH}$ groups on the nanotube surface, aiming to provide covalent bonding with the resin system. CNT papers with a thickness of approx. 200-300 $\mu \mathrm{m}$ were manufactured, with diameters in the range of $31-32 \mathrm{~cm}$ [13]. 
TOSEDA supplied cyanate ester-based prepregs, using a pitch carbon fiber fabric (UD) [Granoc PF(S)-YSH 50A-75 (Mitsui, JP)]. The prepreg sheets used have Fibre Volume Fraction (FVF) of about $50 \%$ and were manufactured using a solvent-based process [14].

The honeycomb used was UCF-126-3/8-2.0 RS3 with YSH50 fibers and cyanate ester resin, supplied by Ultracore (Table 4.5).

Table 4.5: Resume of the materials used [15].

\begin{tabular}{lll}
\hline Materials & Main characteristics & Supplier \\
\hline CNT skeleton & -COO groups, 6,96-7,42 mg/ $\mathrm{cm}^{2}, 31-32 \mathrm{~cm}$ diameter & FutureCarbon \\
Resin & $\begin{array}{l}\text { CE Primaset DT4000 (included as prepreg matrix) } \\
\text { Carbon fiber }\end{array}$ & $\begin{array}{l}\text { Granoc PF(S)-YSH50A-75 } 75 \mathrm{~g} / \mathrm{m}^{2} \\
\text { (included as prepreg reinforcement) }\end{array}$ \\
Honeycomb & 4 pieces $100 \times 200 \mathrm{~mm}^{2}$, UCF-126-3/8-2.0 RS3 & Nippon \\
Adhesive film & Redux 312L & Ultracore \\
Prepregs & Average carbon fabric volume concentration in prepreg 51 vol\% & Hexcel \\
\hline
\end{tabular}

The mold used for manufacturing the CNT-CFRP mirror was made from Invar, with a nickel surface treatment. The active surface of the mold, however, was machined with sharp tolerances to give the mirror the best surface accuracy possible before the polishing operations.

The prepregs manufacturing process includes the following steps:

- Impregnation of Granoc fabric with cyanate ester resin diluted to 35\% in acetone

- Air-drying of the impregnated prepregs to remove the solvent (acetone concentration $<3 \%$ )

- Cutting the air dried pre-preg sheets into the requested size followed

- Marking one corner of the prepreg sheets to keep the same orientation of the carbon fabric fibers (warp and weft)

- Placement of the prepregs between PP foils for protection against bonding during storage and transport.

\subsubsection{Sample manufacturing}

After several manufacturing methodologies used (mainly deriving from the presence of cracks on the CNT surface, which are presented below), the procedure for manufacturing the mirror demonstrator was defined as follows:

1. Cut the CNT BP using a clean sharp tool, with the aid of metal plates, if necessary (Figure 4.12).

2. Dry the CNT BP during $16 \mathrm{~h}$ at $110^{\circ} \mathrm{C}$ before stacking the materials. 
3. If necessary, cut the prepregs in the appropriate dimensions (the warp and weft directions of the prepregs are identified).

4. Register the weight, area and thickness of the materials.

5. Place the Teflon release film in the mold and hold the materials by applying an adhesive tape in the corners (Figure 4.13).

6. Prepare the vacuum bag.

7. Place the CNT-BP in the Teflon release film inside the vacuum bag (Figure 4.14).

8. Lay up the two first prepregs layers, taking into account fabric warp and weft directions (Figure 4.15).

9. Close the vacuum bag and apply vacuum during $10 \mathrm{~min}$ with a vacuum level of 800 mbar with a Teflon release film between the prepreg layers and the vacuum bag (Figure 4.16).

10. Repeat the prepreg lay-up procedure until completion.

11. Place the demolding release film as top layer, use breather to eventually absorb excess resin and close the vacuum bag.

12. Apply the vacuum pressure (Figure 4.17). If necessary, the materials can remain under vacuum overnight.

13. Place the materials in the autoclave with the proper curing schedule.
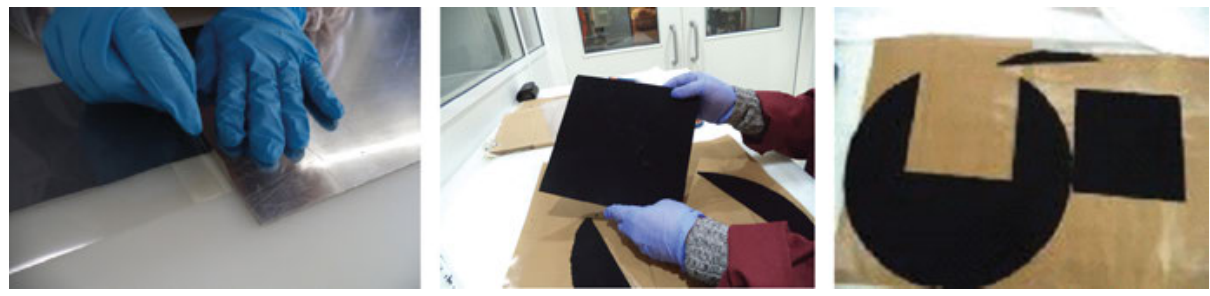

Figure 4.12: Cutting the CNT-BP with the proper size.

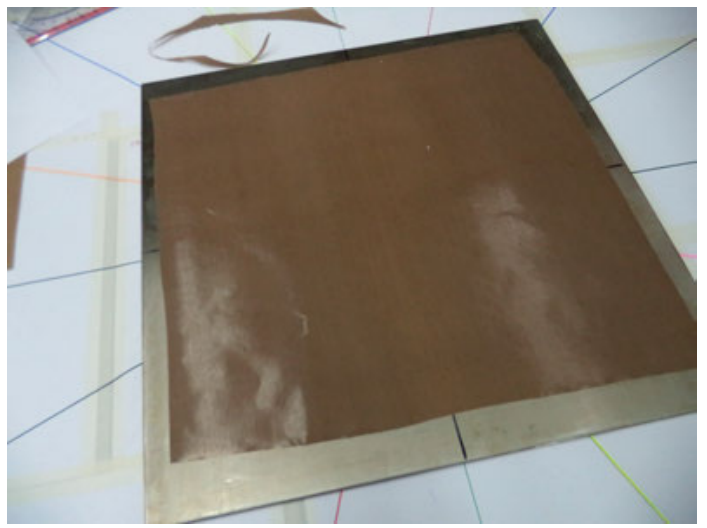

Figure 4.13: Teflon release film. 

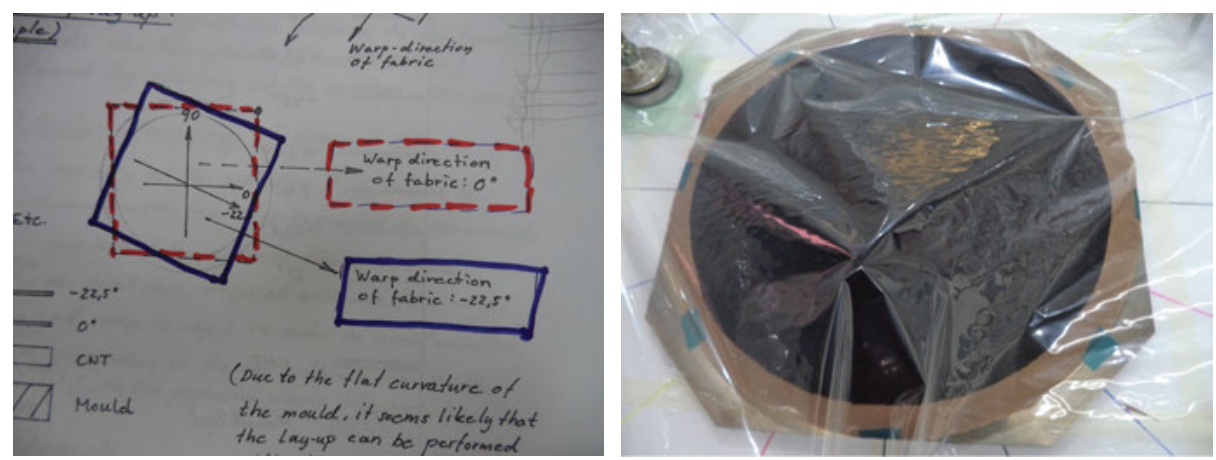

Figure 4.14: CNT-BP facing the mold.
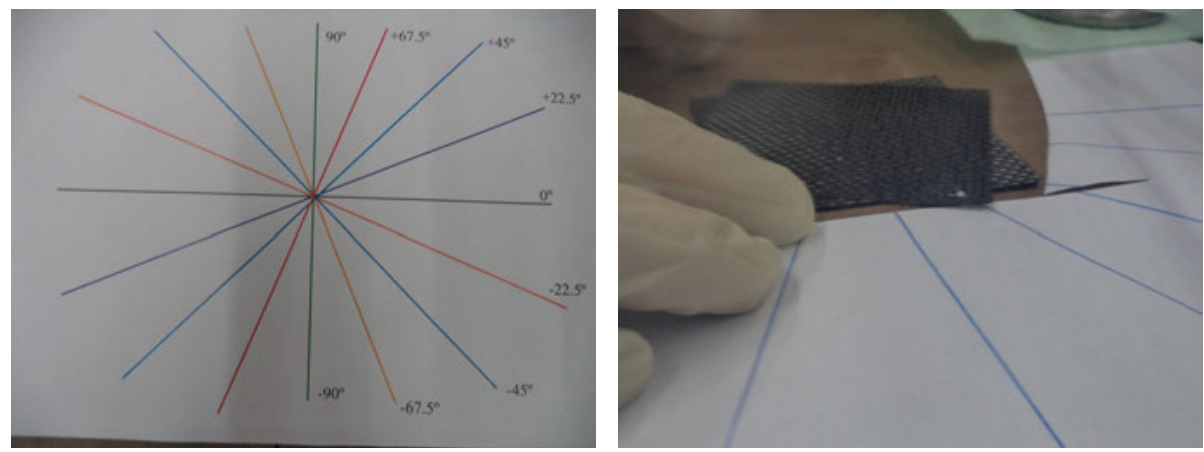

Figure 4.15: Prepreg orientations.
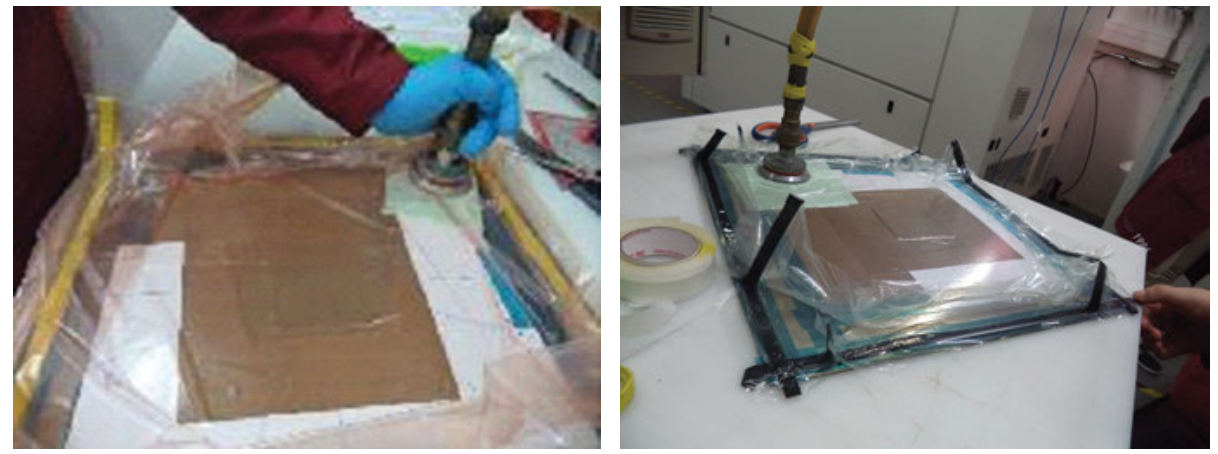

Figure 4.16: Vacuum application. 


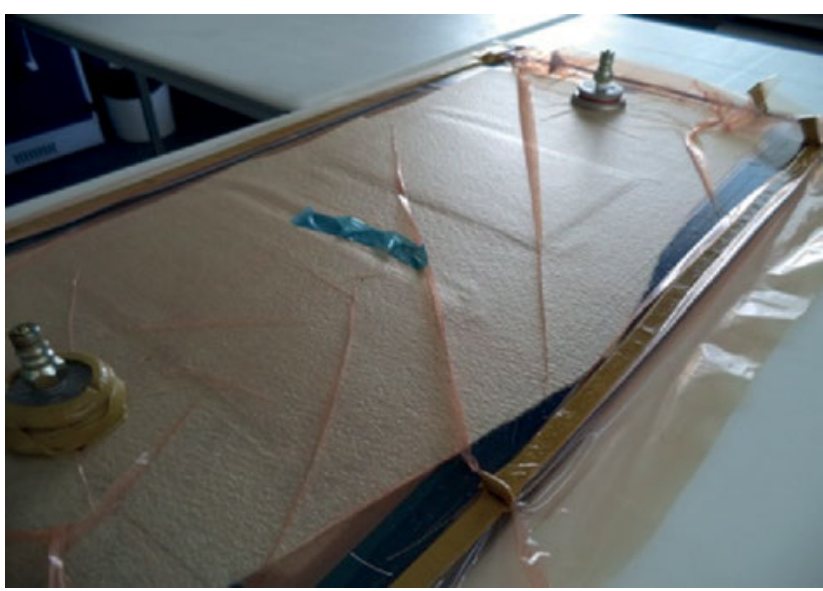

Figure 4.17: Final vacuum-bagged sample, before curing in the autoclave.

\subsubsection{Results and discussion}

\subsubsection{Requirement definitions}

For specifying the optical mirror properties, the nominal requirements for optical surfaces (not superpolished) were used as baseline. The usual base materials for classical optical mirrors are materials like Zerodur (lithium aluminosilicate glass-ceramic produced by Schott AG), Astrositall glass, ULE (ultralow expansion titaniasilicate glass), fused silica, SiC or nickel Canigen. Table 4.6 lists out the requirements [16]:

Table 4.6: CNT-CFRP optical mirror requirements.

\begin{tabular}{ll}
\hline Property & Requirement \\
\hline Mass & At least $20 \%$ less than conventional mirrors \\
Reflectivity & $\mathrm{R}>0.93$ \\
Surface form tolerance & $\mathrm{RMS}<70 \mathrm{~nm}$ \\
Operating temperatures & $-65^{\circ} \mathrm{C} /+45^{\circ} \mathrm{C}$ \\
Nonoperating temperatures & $\pm 120^{\circ} \mathrm{C}$ \\
Outgassing & According to ECSS [17] \\
CME & $24 \mathrm{ppm}$ \\
CTE & $<1 \times 10^{-6}$ \\
Thermal conductivity & $>0.75 \mathrm{~W} / \mathrm{mK}$ \\
Electrical conductivity & $>10^{3} \mathrm{~S} / \mathrm{m}$ \\
\hline
\end{tabular}




\subsubsection{Mirror design}

The design of the mirror demonstrator was performed taking into account both the requirements and material properties. The active surface of the mirror is parabolic, circular symmetric, in order to ease the machining operations. The design (Figure 4.18) is based on a sandwich with a flat skin and a front skin with low curvature, rotationally symmetrical with a radius of curvature of 3,360 $\mathrm{mm}$ [18].

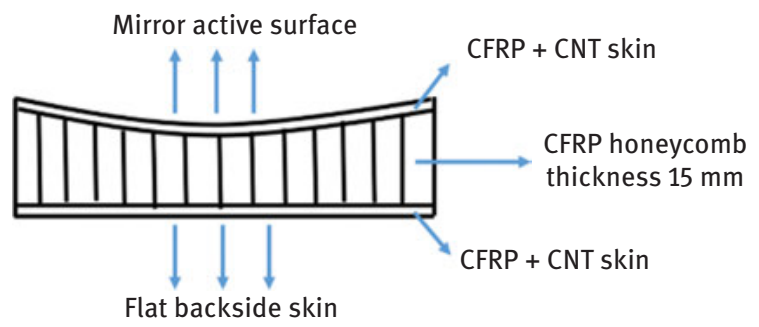

Figure 4.18: CNT-CFRP overall mirror design.

The detailed design also includes the following considerations:

- The reflector sandwich is fully symmetrical in thickness direction.

- Each skin is composed of 16 layers fabric prepreg with surface weight of $75 \mathrm{~g} / \mathrm{m}^{2}$ (without resin) together with a CNT layer.

- The honeycomb is made of CFRP using YSH50A carbon fibers.

- The CNT-CFRP skins are further metalized with vacuum deposit aluminum and protected with a $\mathrm{SiO}_{2}$ layer.

- The adhesive film bonding the CFRP and the honeycomb is based on cyanate ester resin.

- The CTE of the combined skin + CNT + adhesive film shall be zero.

- The CTE of the CFRP honeycomb shall be zero.

- A design of the complete sandwich as close as possible to CTE zero is necessary.

In order to create a very accurate quasi-isotropic lay-up, the following lay-up of the CNT-CFRP layers is proposed. All orientations are based on warp fabric direction, explained in Figure 4.19. 

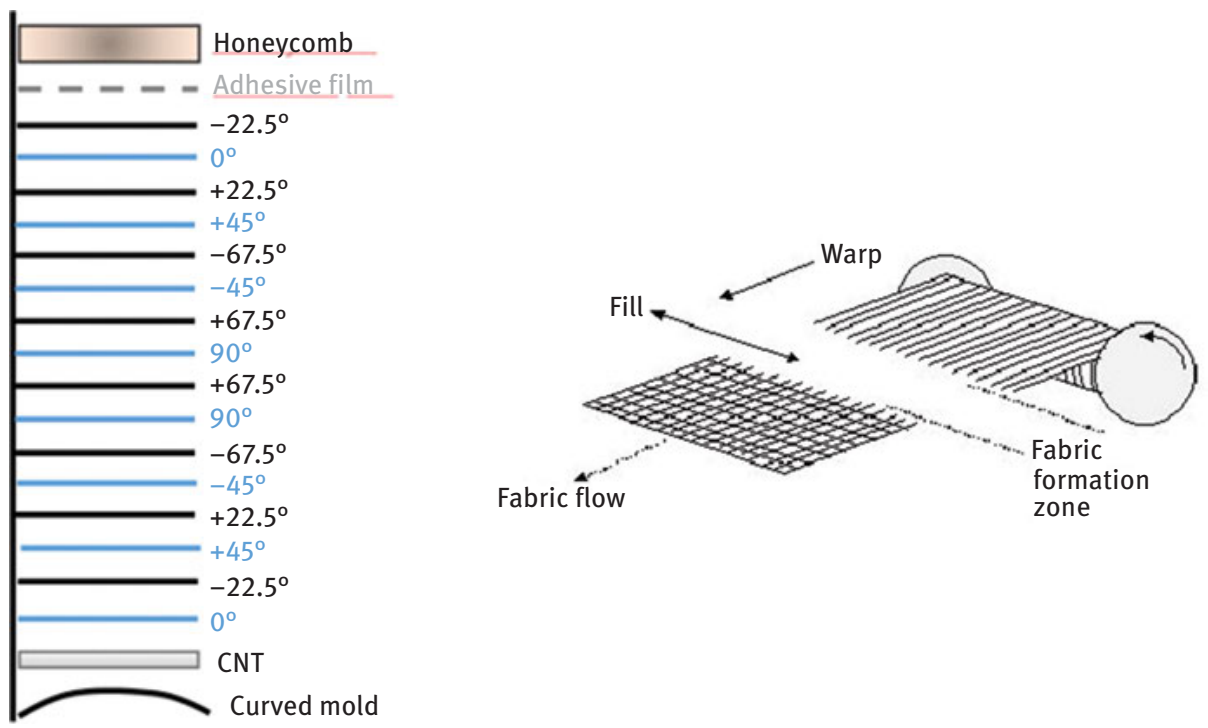

Figure 4.19: CNT-CFRP mirror design: detail of CNT-CFRP skins.

\subsubsection{Manufacturing trials}

NATAP sample manufacturing was performed in several phases. These phases and main objectives of each one are presented in Figure 4.20 [19].

From batch 1 and 2 sample manufacturing, the following conclusions were taken [20]:

- The preimpregnated fiber sheets and BP are easy to manipulate during the manufacturing process - including the production of curved samples - therefore, no major risks are attributed to draping for the expected geometries for the final applications.

- Prepregs prepared for batch 2 with $51 \%$ of FVF were found to be a good approach for manufacturing the demonstrator, since the resin amount present is enough to guarantee a good BP impregnation without the need to add additional resins. The CFRP layers were found to be well compacted, reducing the risk of having dry CFRP layers.

- Theoretical calculations also show that these new prepregs result in a final FVF of approximately $65 \%$, which is a good balance between high fiber volume fraction for increased performance and enough resin to guarantee an homogenous structure of the CFRP structure (if previous prepregs with higher FVF were used, it was expected that composite was significantly dry - with 71-78 vol\% of fiber). 


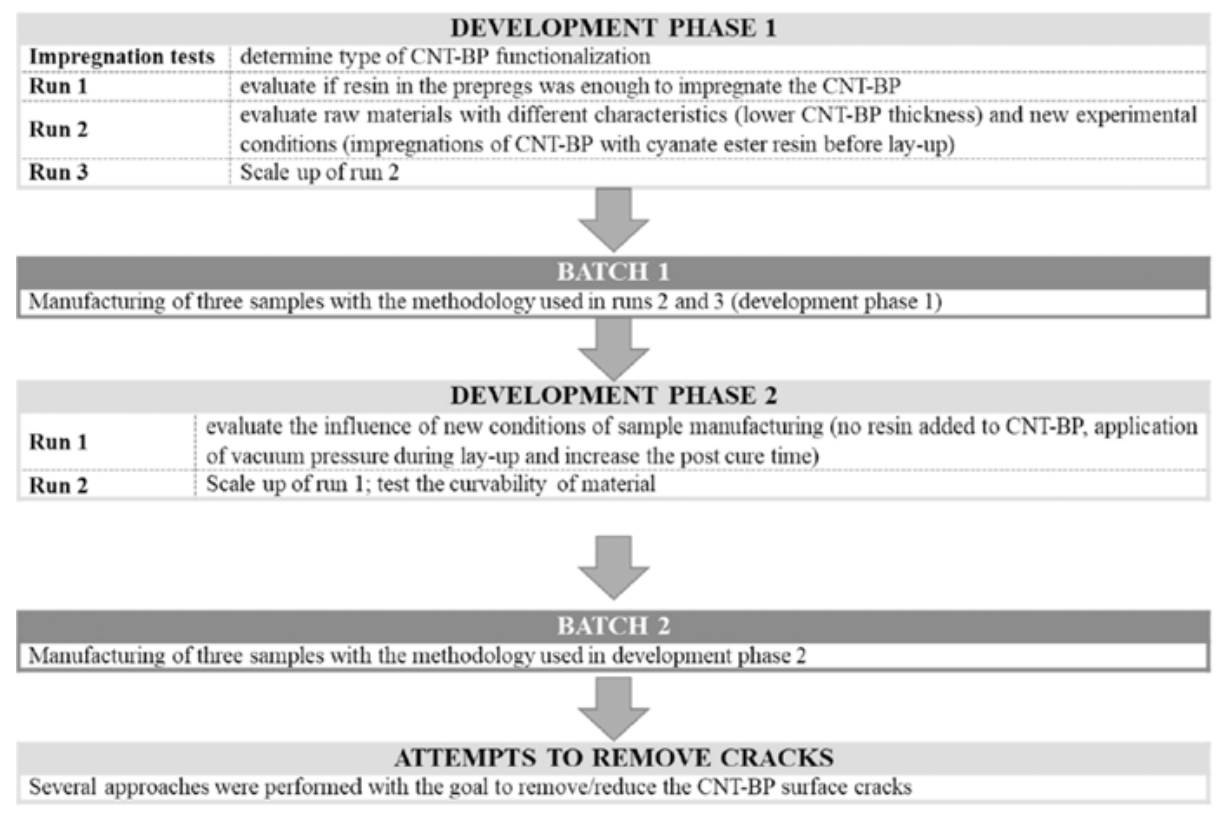

Figure 4.20: NATAP project phases and main objectives of each one.

- The vacuum pressure applied during lay-up is an important step to improve cohesion between layers.

- Curved samples can be manufactured without significant additional effort, however, they were found to be more difficult to demold. It is recommended to coat the curved mold with a Teflon release film with extended length (larger than the mold) to ease the demolding process;

- In batch 2, two main problems were detected: samples warping after cure cycle (only detected during demolding) and some marks on the surface. Warping can be attributed to the formation of tension forces formed during the cure cycle (at high temperatures and due to the geometry of the samples) and, therefore, the prepregs lay-up sequence may be reviewed for specific geometries;

- The existence of a surface pattern is should not be a problem, since the marks are expected to disappear after polishing and metalization processes.

Sample characterizations performed throughout the project allowed to detect some issues are shown below. The actions taken to avoid/eliminate those issues are also presented.

As referred before, some changes were made in both the characteristics of the raw materials used and experimental conditions during sample manufacturing. Figure 4.21 summarizes the experimental conditions, changes in the methodology used and problems encountered in the different stages of NATAP. 


\begin{tabular}{|c|c|c|}
\hline Project phase & Issue & Characterization \\
\hline $\begin{array}{l}\text { Development } \\
\text { phase 1: Run } 1\end{array}$ & $\begin{array}{l}\text { Dry CNT structure, } \\
\text { only bonded to } \\
\text { CFRP at the ends }\end{array}$ & $\begin{array}{l}\text { Detail showing the adherence only in the edges of the CNT } \\
\text { layer and the carbon fiber; the CNT structure is dry }\end{array}$ \\
\hline Batch 1 & $\begin{array}{l}\text { CNT BP thickness } \\
\text { after impregnation } \\
\text { was higher than } \\
\text { expected (BP } \\
\text { expands with } \\
\text { resin addition) }\end{array}$ & $\begin{array}{l}\text { Cross-sectional view performed by } \\
\text { AAC (BP-impregnated average } \\
\text { thickness } 430 \mu \mathrm{m}) / \\
\text { nonimpregnated CNT BP average } \\
\text { thickness }\end{array}$ \\
\hline
\end{tabular}

\begin{tabular}{|c|c|c|c|}
\hline Batch 1 & $\begin{array}{l}\text { Presence of cracks } \\
\text { in the CNT BP } \\
\text { structure }\end{array}$ & $\begin{array}{l}\text { SEM images of coat } \\
\text { provided by AAC, sh }\end{array}$ & $\begin{array}{l}\text { urface mirror sample of batch } 1 \\
\text { ng the existence of cracks }\end{array}$ \\
\hline Batch 1 & $\begin{array}{l}\text { Glass transition } \\
\text { temperature lower } \\
\text { than expected }\end{array}$ & Theasurements $\mathrm{pe}$ & med by AAC \\
\hline $\begin{array}{l}\text { Development } \\
\text { phase 2: Run } 1\end{array}$ & Lack of resin & $\begin{array}{l}\text { BP surface (before } \\
\text { impregnation) - } \\
\text { marks are visible }\end{array}$ & $\begin{array}{l}\text { Cross-sectional SEM picture, } \\
\text { showing that the structure is dry } \\
\text { (low resin content); bright surface } \\
\text { shows that the BP is well } \\
\text { impregnated }\end{array}$ \\
\hline
\end{tabular}


(continued)

\begin{tabular}{lll}
\hline Project phase & Issue & Characterization \\
\hline Batch 2 & $\begin{array}{l}\text { Cracks on CNT-BP } \\
\text { structure }\end{array}$ & \\
& & Cross-sectional view performed by AAC. Cracks are visible. \\
\hline
\end{tabular}

\subsubsection{Mirror demonstrator manufacturing}

The main steps taken in the demonstrator manufacturing are summarized as follows [15]:

1. Mold preparation

2. Back skin manufacturing

3. Front skin manufacturing

4. Bonding honeycomb to front skin

5. Honeycomb machining

6. Back skin bonding to honeycomb (final assembly)

7. Final machining

Back and front skins were prepared according to the stacking sequence previously presented. Figure 4.22 shows the aspect of both CNT-CFRP skins after demolding (Figures 4.23-4.25).

The first assembly step consisted in bonding the honeycomb to the front skin. The CNT-CFRP skin was placed in the mold and prepared for the adhesive and honeycomb settlement. Afterward, the assembly was placed in the oven under vacuum pressure and temperature cycles.

After the first assembly, the honeycomb was machined on the free side in order to have a flat surface, for further bonding with the back skin bonding. A flat disk installed in a defined position in the turning machine was used for the in-house machining process.

The final assembly consisted in bonding the back skin to the first assembly. The back skin, containing adhesive, was placed on the top of the machined honeycomb. The entire assembly was then placed in the oven under vacuum pressure and temperature cycles. 


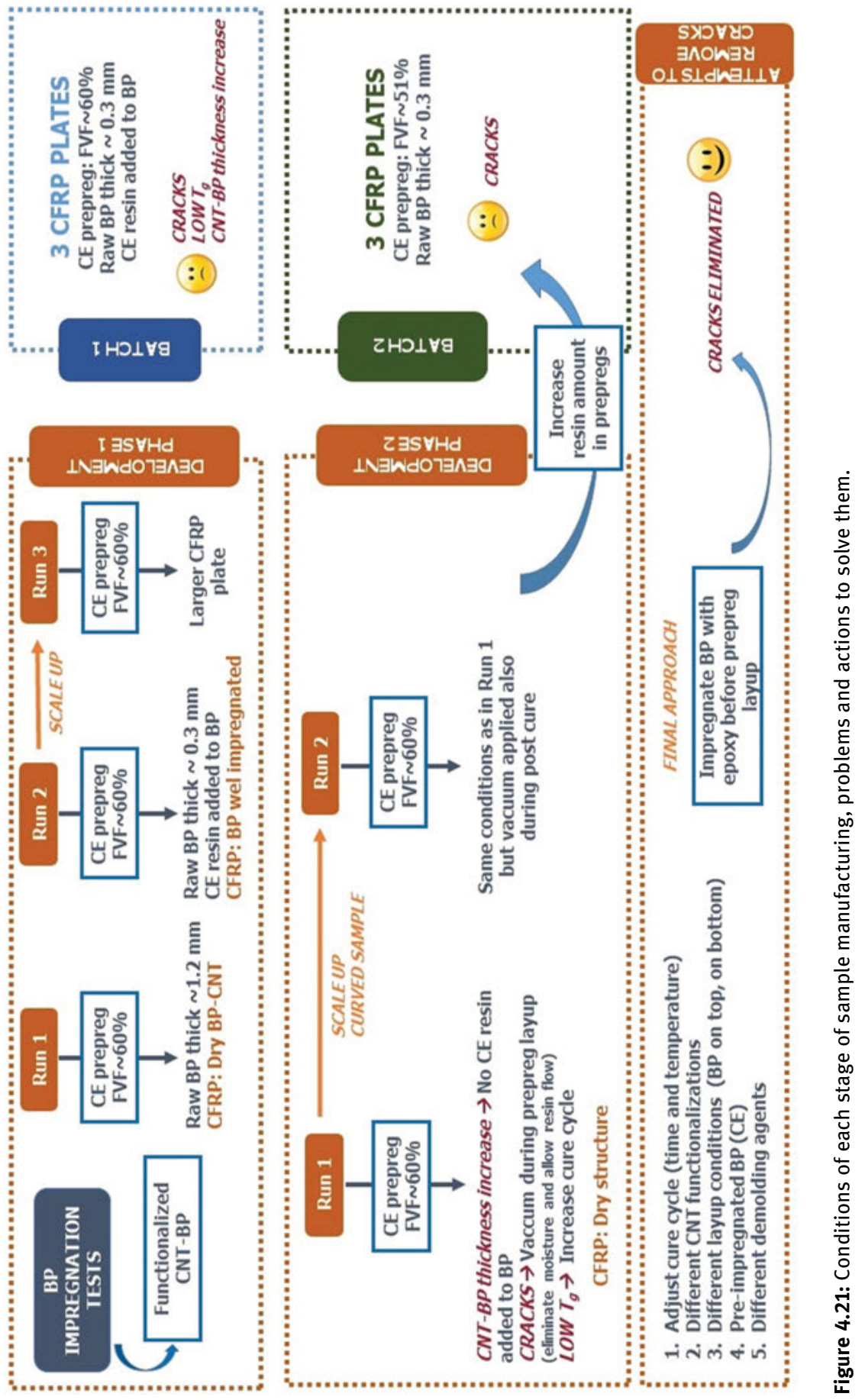




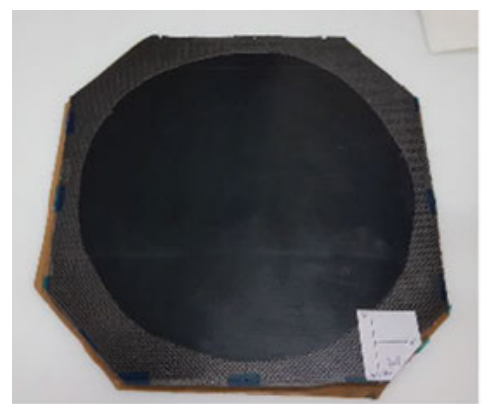

(a)

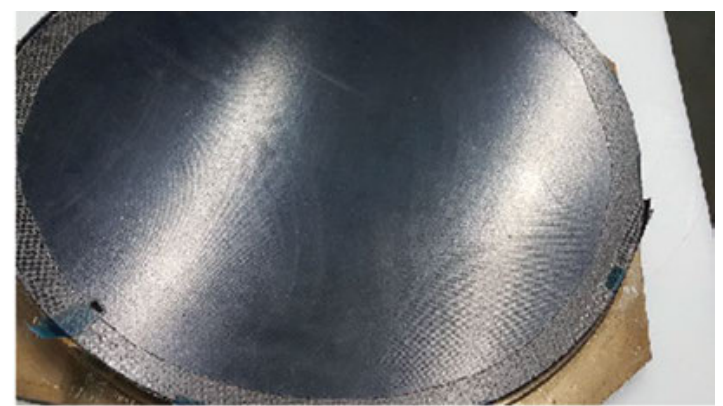

(b)

Figure 4.22: (a) Mirror back skin and (b) mirror front skin.

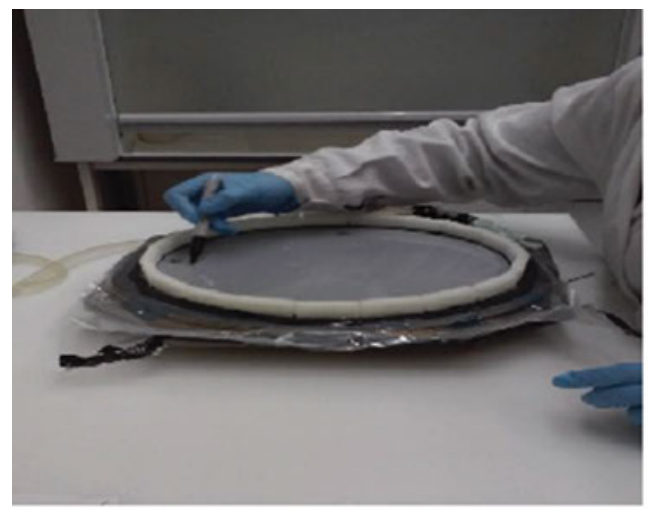

(a)

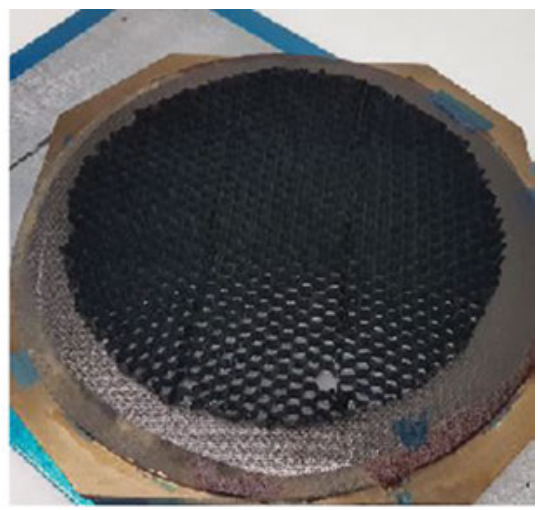

(b)

Figure 4.23: (a) Application of adhesive and (b) view of the honeycomb bonded to front skin.

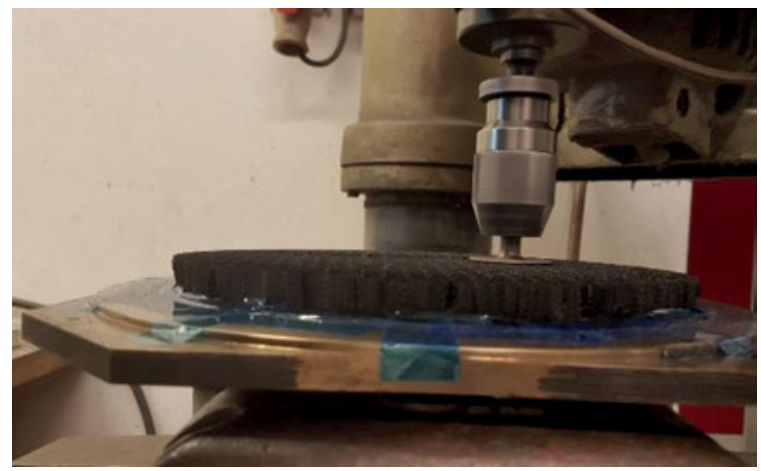

Figure 4.24: Honeycomb machining to obtain a flat surface. 


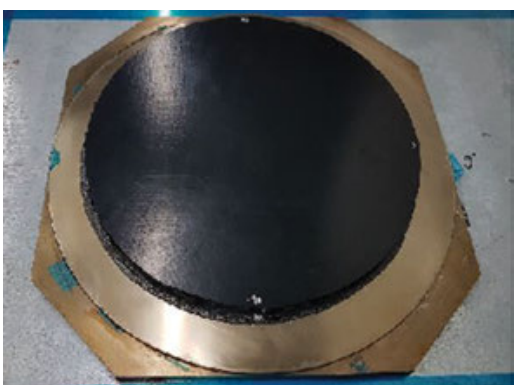

(a)

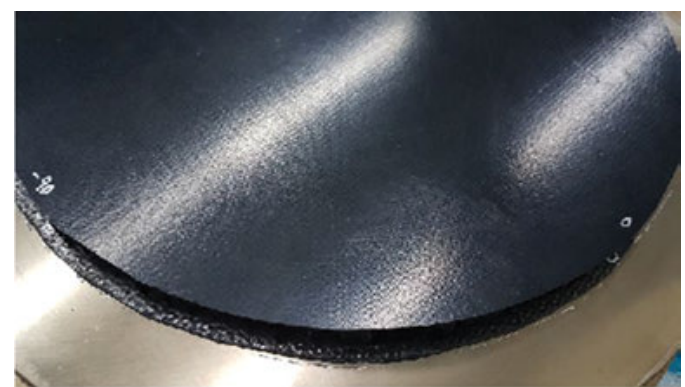

(b)

Figure 4.25: (a) Assembly after curing with the back skin in the top. (b) Detail of the back surface, where no cracks are visible after all the assembly operations.

\subsubsection{Mirror polishing and metalization}

One of the project goals was to determine the most suitable polishing process conditions applicable on CNC polishing machines and allowing to achieve targeted microroughness $\mathrm{Rq}(\mathrm{Sq})$ of $10-15 \mathrm{~nm}$ on the optical mirror surface. The individual work steps are summarized as follows [21]:

\subsubsection{Polishing}

- Machining outside diameter

- Smoothing an optical surface

- Surface form correction

- Roughness correction

\subsubsection{Metalization}

- By vacuum deposition using e-beam evaporator unit.

The selected technologies were:

- Polishing by two-step process using $\mathrm{CeO}_{2}$ polishing slurry and polyurethane pad

- Metalization by physical vapor deposition (PVD) technology (e-beam evaporator)

Figure 4.26 shows the surface appearance of a CNT-CFRP skin after the polishing procedure and the surface microroughness of that surface measured using an interferometer, showing that the surface root mean square height $(\mathrm{Sq})$ value is $11.82 \mathrm{~nm}$. 


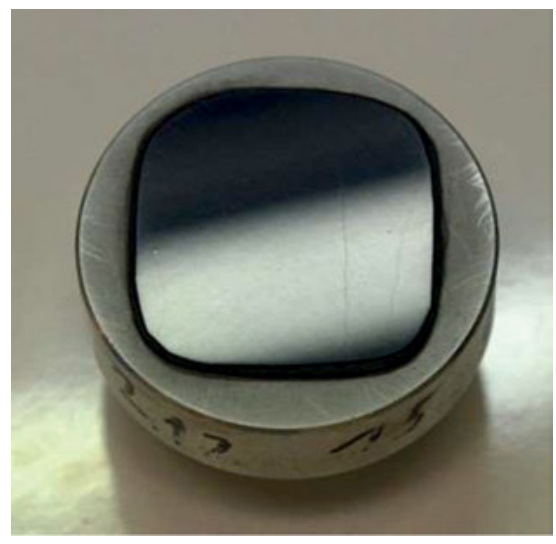

(a)

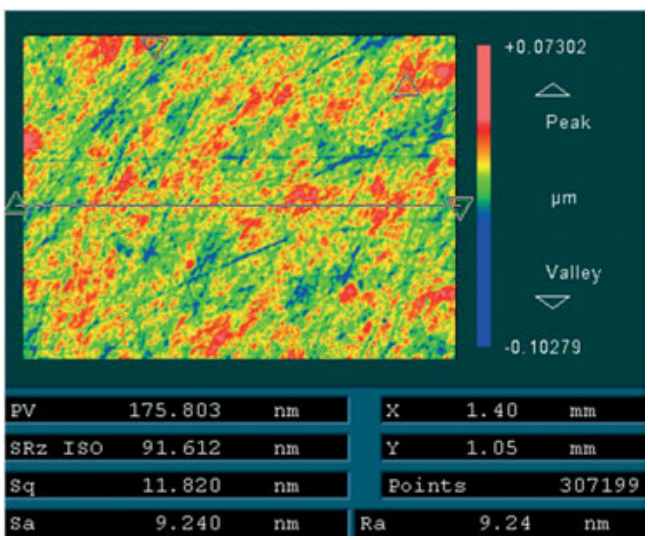

(b)

Figure 4.26: (a) Surface appearance of CNT-CFRP skin after polishing and (b) interferometer results after polishing.

The polished CNT surface of the optical mirror was coated by combination of $\mathrm{Al}$ $(100-120 \mathrm{~nm})$ and $\mathrm{SiO}_{2}(70 \mathrm{~nm})$ protective layer without loss of adhesion. This combination is a standard type of coating for optical mirrors. $\mathrm{SiO}_{2}$ greatly increases durability of the surface (protection of the Al coating against oxidation). Resulting mirror surface has good abrasion resistance, but the top CNT layer of the composite is soft (compared to ceramics and glasses); hence, the optical mirror surface can be damaged due to damage of the CNT layer.

The achieved RMS value of $412 \mathrm{~nm}$, which included the outer border, does not reach the target value of $70 \mathrm{~nm}$. A reduction of the effective area to exclude the edge effect enhances the RMS to $\sim 230 \mathrm{~nm}$, which still is not sufficient for the targeted quality.

Nevertheless, the quality is well passing the necessary surface quality for the backup option of the radiometer example MetOp, where 1,000 $\mathrm{nm}$ is targeted.

Further improvements on RMS quality will be possible when the print-through of the backing structure as well as the cracks in the CNT layer can be reduced or, respectively, avoided.

An enhancement of hardness of the top layer could improve the local roughness, which has been measured to be in the range of $10 \mathrm{~nm}$ [22].

\subsubsection{Mechanical characterization}

The mechanical properties have been determined at ambient temperature before thermal cycling (RT) and after thermal cycling (RT, TC), and at the maximal $\left(120^{\circ} \mathrm{C}\right)$ and minimal $\left(-120^{\circ} \mathrm{C}\right)$ nonoperational temperatures foreseen for the respective 
application. The summary of determined mechanical properties for the mirror is shown in Table 4.7. The measured density of the material was $1.493 \pm 0.015 \mathrm{~g} / \mathrm{cm}^{3}$.

Table 4.7: Summary of mirror mechanical properties [19].

\begin{tabular}{lrrrrr}
\hline Temperature $\left(^{\circ} \mathrm{C}\right)$ & $\begin{array}{r}\text { 3-Point } \\
\text { bending } \\
\text { strength } \\
(\mathrm{MPa})\end{array}$ & $\begin{array}{r}\text { Young's } \\
\text { modulus } \\
(\mathrm{GPa})\end{array}$ & $\begin{array}{r}\text { 4-Point } \\
\text { bending } \\
\text { strength } \\
(\mathrm{MPa})\end{array}$ & $\begin{array}{r}\text { Young's } \\
\text { modulus } \\
(\mathrm{GPa})\end{array}$ & $\begin{array}{r}\text { Interlaminar } \\
\text { shear }\end{array}$ \\
\hline-120 & $282.8 \pm 12.9$ & $24.9 \pm 1.4$ & $324.7 \pm 16.7$ & $27.7 \pm 1.5$ & $29.1 \pm 1.6$ \\
ST & $284.6 \pm 9.9$ & $31.9 \pm 1.6$ & $270.5 \pm 5.5$ & $29.1 \pm 1.1$ & $26.2 \pm 1.4$ \\
+120 & $262.2 \pm 5.9$ & $24.9 \pm 2.7$ & $236.6 \pm 6.3$ & $32.4 \pm 1.3$ & $23.6 \pm 1.1$ \\
RT, TC & $251.2 \pm 11.1$ & $28.6 \pm 1.6$ & $254.5 \pm 9.2$ & $27.0 \pm 0.5$ & $27.1 \pm 1.2$ \\
\hline
\end{tabular}

Summarizing all the above presented results, the mechanical properties of the materials are considered suitable for the application with sufficient safety margin.

\subsubsection{Electrical characterization}

A total of four measurement points were performed onto the antenna polished and metallized surface; three to be placed at the outer circumference of the antenna and one into the center (Table 4.8).

Table 4.8: Radial positions for electrical measurements.

\begin{tabular}{lll}
\hline Position & Code & Details \\
\hline 1 & FS-R1 to FS-C & Front side radial-1 to front side-center \\
2 & FS-R2 to FS-C & Front side radial-2 to front side-center \\
3 & FS-R3 to FS-C & Front side radial-3 to front side-center \\
4 & FS-R1 to FS-R2 & Front side radial-1 to front side-2 \\
5 & FS-R1 to FS-R3 & Front side radial-1 to front side-3 \\
6 & FS-R2 to FS-R3 & Front side radial-2 to front side-3
\end{tabular}

The DC resistance using a Metrohit Multimeter was measured from each of the three radial positions (FS-R1 to FS-R3) to the center FS-C (Figures 4.27 and 4.28).

The results of this test are shown in Table 4.9. The standard deviation of the measurements before thermal cycling is very high. A reason for this can be a capacitor effect of the honeycomb structure under the surface.

The electrical conductivity after the thermal tests was much higher than before the thermal cycling. The reason for this can be the many small cracks of the metalized surface; therefore, the insulating silica top layer was probably fractured, exposing 


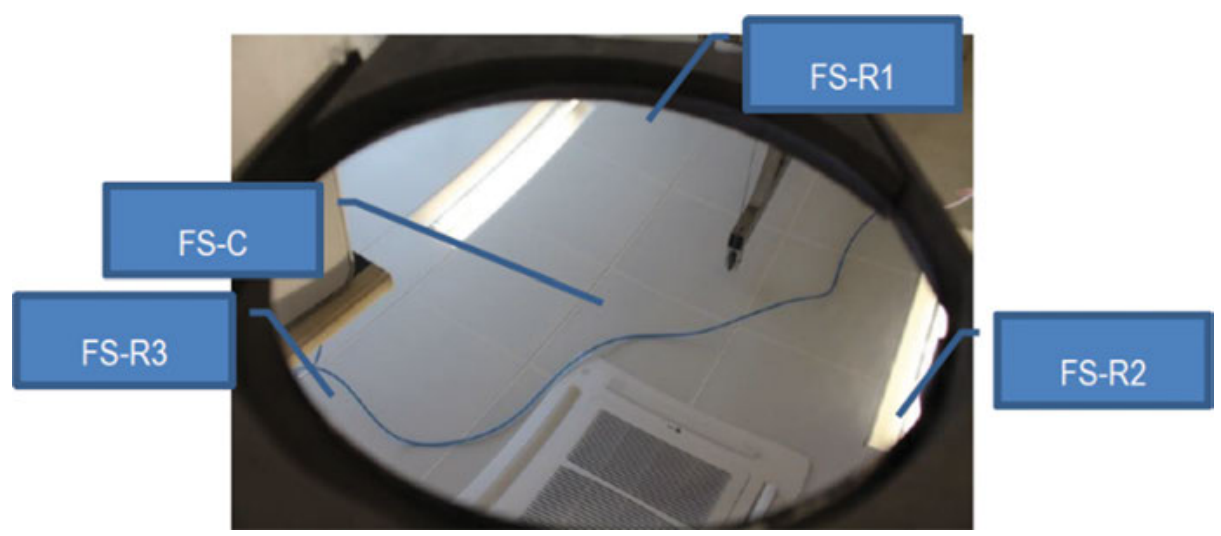

Figure 4.27: Electrical surface resistance test.
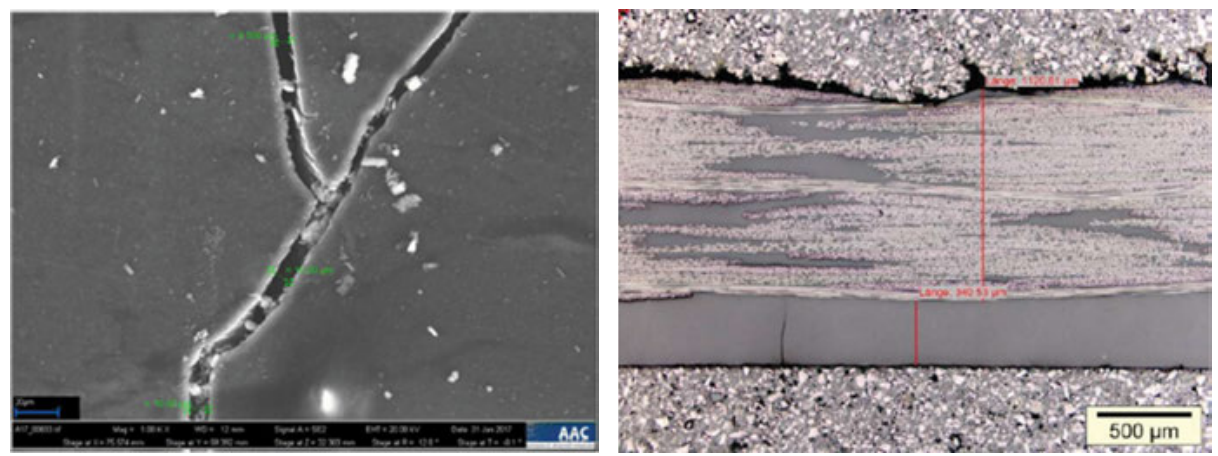

Figure 4.28: Surface crack in mirror sample after thermal cycling (left), Cross section of mirror sample (right).

Table 4.9: Summary of electrical measurement results.

\begin{tabular}{lcrrrrr}
\hline Code & \multicolumn{2}{c}{ Before thermal cycling } & & \multicolumn{2}{c}{ After thermal cycling } \\
\cline { 2 - 3 } & Average $(\boldsymbol{\Omega})$ & $\begin{array}{r}\text { Standard } \\
\text { deviation }\end{array}$ & $\begin{array}{rrrrr}\text { Conductivity } \\
(\mathbf{S} / \mathbf{m})\end{array}$ & & Average $(\boldsymbol{\Omega})$ & $\begin{array}{r}\text { Standard } \\
\text { deviation }\end{array}$ \\
\hline FS-R1 to FS-C & $9,166.7$ & 1040.8 & $9,92 \mathrm{E}-04$ & & 21.7 & 7.2 \\
FS-R2 to FS-C & $6,166.7$ & 1040.8 & $1.47 \mathrm{E}-03$ & & 13.0 & 4.2 \\
FS-R3 to FS-C & $3,600.0$ & 1216.6 & $2.53 \mathrm{E}-03$ & & 21.3 & 4.6 \\
FS-R1 to FS-R2 & $2,066.7$ & 378.6 & $2.42 \mathrm{E}-03$ & & 27.1 & 5.8 \\
FS-R1 to FS-R3 & $2,000.0$ & 435.9 & $2.50 \mathrm{E}-03$ & & 23.3 & 2.5 \\
FS-R2 to FS-R3 & $2,566.7$ & 907.4 & $1.95 \mathrm{E}-03$ & & 22.7 & 3.0 \\
\hline
\end{tabular}


either the aluminum or the CNT layer, and we could measure the electrically conductive surface through the top layer.

The requirement of $10^{3} \mathrm{~S} / \mathrm{m}$, that is, "metallic" electrical conductivity, could not be reached. The as-received surface conductivity was $4.28 \mathrm{~S} / \mathrm{m}$ for the CNT side and $2.59 \mathrm{~S} / \mathrm{m}$ for the CFRP side. Careful roughening the surface with Grit 1200 sandpaper improved the surface conductivity substantially to $4.28 \mathrm{~S} / \mathrm{m}$ for the CNT side, and $16.18 \mathrm{~S} / \mathrm{m}$ for the CFRP side where carbon fibers were apparently contacted.

\subsubsection{Thermo-optical properties}

Thermo-optical properties were tested at ZAE Würzburg, each for the CNT and for the CFRP side. The thermo-optical properties do not differ from CFRP to CNT side (Table 4.10).

Table 4.10: Summary of mirror absorbance values.

\begin{tabular}{lrrr}
\hline Sample & Visual absorbance & Solar absorbance & UV absorbance \\
\hline CFRP face & $0.92 \pm 0.02$ & $0.91 \pm 0.02$ & $0.93 \pm 0.02$ \\
CNT face & $0.94 \pm 0.02$ & $0.94 \pm 0.02$ & $0.94 \pm 0.02$ \\
\hline
\end{tabular}

\subsubsection{Structure observations}

The mirror samples consisted of about 1.1-1.2 mm CFRP, and a CNT layer of about $350 \mu \mathrm{m}$. The surface shows cracks after thermal cycling.

Table 4.11 summarizes the main results achieved with the CNT-CFRP mirror, highlighting that mass, CTE and thermal conductivity properties achieved are in high-performance levels; however, specific heat, surface accuracy and reflectivity values are below the requirement definitions.

\subsubsection{Conclusions}

The selected demonstrator - a CFRP-based mirror - was manufactured using two CFRP skins based on cyanate ester prepregs, with BP on the top surface. The CNT structure was incorporated as top layer of the skin during prepregs lay-up and then impregnated with the resin from prepregs. These CFRP skins were assembled with a CFRP honeycomb for obtaining the final part, further polished and metalized. Mirror mass was significantly improved at very good thermoelastic distortion values, but the CNT surfaces have many cracks, which further propagated after thermal cycling. 
Table 4.11: Optical mirror demonstrator - major results.

\begin{tabular}{lll}
\hline Property & Results & $\begin{array}{l}\text { Performance } \\
\text { level }\end{array}$ \\
\hline Mass & $\begin{array}{l}\text { More than } 20 \% \text { mass saving in relation to a conventional } \\
\text { optical mirror can be achieved. The mirror demonstrator’s } \\
\text { mass was only } 270 \mathrm{~g} .\end{array}$ & ++ \\
\hline CTE & $-0.706 \times 10^{-6} / \mathrm{K}$ in $\mathrm{X} / \mathrm{Y}$-direction (requirement: $\left.< \pm 1 \times 10^{-6} / \mathrm{K}\right)$ & ++ \\
\hline $\begin{array}{l}\text { Thermal } \\
\text { conductivity }\end{array}$ & $0.84 \mathrm{~W} /\left(\mathrm{m}^{\star} \mathrm{K}\right)$, better than required $\left(>0.75 \mathrm{~W} /\left(\mathrm{m}^{\star} \mathrm{K}\right)\right)$ & + \\
\hline Specific heat & $0.73 \mathrm{~J} /\left(\mathrm{kg}{ }^{\star \circ} \mathrm{C}\right)$ acceptable in relation to Zerodur $0.85 \mathrm{~J} /\left(\mathrm{kg}{ }^{\star \circ} \mathrm{C}\right)$ & - \\
\hline Surface accuracy & $\begin{array}{l}0.135 \mu \mathrm{m} \text { has been reached, not far away from requirements } \\
(<0.1 \mu \mathrm{m})\end{array}$ & - \\
\hline Surface quality & Not reached - presence of many cracks & - \\
\hline Reflectivity & $\begin{array}{l}0.7(\text { after cycling), required value }(>0.93) \text { not reached due to } \\
\mathrm{cracks} \text { in surface }\end{array}$ & -- \\
\hline $\begin{array}{l}\text { Temperature } \\
\text { range }\end{array}$ & $-120^{\circ} \mathrm{C} \rightarrow+100^{\circ} \mathrm{C}$ & \\
\hline
\end{tabular}

Several development steps were performed, aiming to eliminate or reduce the formation of cracks, such as the study of the influence of the lay-up, curing conditions and mold conditions, but none of the proposed approaches was effective. After all physical parameters being tested, the chemical influence of the resin was investigated. The cracks were eliminated by replacing the CTE for an epoxy resin in the CNT layer.

In fiber-reinforced composites, the CTE is affected primarily by the carbon fibers, while on the CNT layer, the resin CTE has the dominant effect. CTE disproportion can generate fatal stresses.

\subsection{Conclusions}

In this chapter, we presented a brief overview of the activities performed under three ESA projects, as well as the main results, targeting the use of CNT structures in the space sector. The first project was intended to prove the feasibility of CNT structures $\mathrm{BP}$ - to be infiltrated with an organic matrix, potentially as an alternative to poorly dispersed and high viscosity nanotube-filled resin systems. Focus was given on assessing the morphology of the developed materials, by using high-resolution 
microscopic analyses. The results show the proposed processing approach as capable of producing well-dispersed nanocomposites with high CNT loading (more than 15 wt $\%$ CNT by composite weight), which are important for developing highperformance structures based on CNT with good thermal and electrical conductivity.

The main objective of this activity was to scale up the material developments and thereby increase the Technology readiness level (TRL) to 2 for CNT skeletonbased polymer composites. The developed materials are used for manufacturing and testing of demonstrators for typical space applications. Several experimental trials were performed, trying to optimize process conditions such as mold tools, curing conditions or the use of different methods for BP impregnation. In a first step, the manufacturing process for obtaining CNT-skeletons with well-defined and reproducible characteristics was followed. In a second step, the composite manufacturing processes were further developed on sample level and in parallel the dimensions of the CNT-skeletons were scaled up to $0.1 \mathrm{~m} \times 1 \mathrm{~m}$ with thickness ranging from few tens of micrometers up to few centimeters. In the third step, the CNT-reinforced composite manufacturing was stabilized on scaled-up dimensions, suitable for manufacturing technological demonstrators. It was possible to obtain CFRP/CNT skeleton composites based on small papers in a controlled manner, with high CNT content, no defects and voids and without excess of resin in top, interlayer and bottom surfaces.

The final activity targeted a space application, and a demonstrator was manufactured and tested during the project. The selected application was an optical mirror, in which the CNT structures were intended to improve the surface characteristics of the material, facilitating the polishing and metalization steps. Extensive mechanical, thermal and optical characterizations were performed at sample and demonstrator level. The CNT-CFRP mirror resulted in more than $20 \%$ of mass savings, when compared to a conventional mirror, with a final mass of only $270 \mathrm{~g}$. The measured surface accuracy was of $0.135 \mu \mathrm{m}$, not much distant of requirements $(<0.1 \mu \mathrm{m})$. The main issue of the optical mirror is related to the presence of several cracks on the CNT layer, limiting the surface quality and the reflectivity values obtained. Nevertheless, the principle of producing a highly accurate optical mirror based on a CFRP/CNT is rated as promising, with good thermoelastic distortion values. It is estimated that a TRL level between 3 and 4 has been reached.

Acknowledgments: The authors thank the financial support from the European Space Agency (ESA) under the frame of the following projects:

- Non-conventional Matrix/CNT Reinforced Composite for Applications in Space (NACO), Contract 20521/06/NL/SFe

- Non-conventional Matrix/CNT Reinforced Composite 2, Contract 4000104354/ 11/NL/RA

- Carbon Nanotube Technology and Material Engineering for Various Space Applications (NATAP), Contract 4000116757/16/NL/LvH/fg 


\section{References}

[1] NACO-FCA-TN-06, Optimization Procedures and CNT Network Characteristics

[2] NACO-INE-TN, Production of CNT-PMC at INEGI- first trials

[3] Abdalla, M., Dean, D., Robinson, P. and Nyairo, E., "Cure behavior of epoxy/MWCNT nanocomposites: the effect of nanotube surface modification”, Polymer 49 (2008), 3310-3317

[4] Wang, Z., Liang, Z., Wang, B., Zhang, C. and Kramer, L., "Processing and property investigation of single-walled carbon nanotube (SWNT) buckypaper/epoxy resin matrix nanocomposites"; Composites: Part A 35 (2004) 1225-1232

[5] Lopes, P.E. et al. Composite Structures 92 (2010) 1291-1298

[6] Gojny F., Wichmann, M.H.G., Fiedler, B., Bauhofer, W., Windle, A. H., Schulte, K. Polymer 47 (2006), 2036-2045

[7] Hernández-Pérez, A., Avilés, F., May-Pat, A., Valadez-González, A., Herrera-Franco, P. J. and Bartolo-Pérez, P., "Effective properties of multiwalled carbon nanotube/epoxy composites using two different tubes", Composites Science and Technology 68 (2008) 1422-1431

[8] Gonnet, P., Liang, Z., Choi, E. S., Kadambala, R. S., Zhang, C., Brooks, J. S., Kramer, L., "Thermal conductivity of magnetically aligned carbon nanotube buckypapers and nanocomposites”, Current Applied Physics, 6 (2006), 119-122

[9] Non-Conventional Matrix/CNT Reinforced Composite 2, NACO2-INE-TN-240, Polymer CNTComposite 1 Development and Test

[10] Non-Conventional Matrix/CNT Reinforced Composite 2, NACO2-HPS-RP-100, Summary Report

[11] Non-Conventional Matrix/CNT Reinforced Composite 2, NACO2-INE-TN-312, Polymer Demonstrator Report

[12] Carbon Nanotube Technology and Material Engineering for Various Space Applications (NATAP), NATAP-HPS-TN-110, Selection of Space Applications and Associated Requirements

[13] Carbon Nanotube Technology and Material Engineering for Various Space Applications (NATAP), NATAP-FC-TN-211 Production of Composite Samples and Breadboards Batch 1 \& 2

[14] Carbon Nanotube Technology and Material Engineering for Various Space Applications (NATAP), NATAP-TOS-E-TN215, Production of composite samples and breadboards: Batch 1 \& 2

[15] Carbon Nanotube Technology and Material Engineering for Various Space Applications (NATAP), NATAP-HPSP-TN-351, Mirror Demonstrator Manufacturing

[16] Carbon Nanotube Technology and Material Engineering for Various Space Applications (NATAP), NAT-KTO-RS-001, Mirror Specifications

[17] ECSS-Q-ST-70-02C, Thermal vacuum outgassing test for the screening of space materials, 15 November 2008

[18] Carbon Nanotube Technology and Material Engineering for Various Space Applications (NATAP), NATAP-HPS-TN-120, Preliminary concept for demonstrator optical mirror

[19] Carbon Nanotube Technology and Material Engineering for Various Space Applications (NATAP), NATAP-HPS-RP-200, Final Report

[20] Carbon Nanotube Technology and Material Engineering for Various Space Applications (NATAP), NATAP-INE-TN2.1.3, Production of Material and Subelement Specimens 2

[21] Carbon Nanotube Technology and Material Engineering for Various Space Applications (NATAP), NATAP-TOS-E-TN351, Demonstrator 1 Manufacturing

[22] Carbon Nanotube Technology and Material Engineering for Various Space Applications (NATAP), NATAP-AAC-TN-400, Test Report Demonstrator Manufacturing 
